\title{
Digital Governance in Developing Countries: Beneficiary Experience and Perceptions of System Reform in Rajasthan, India
}

\section{Alan Gelb, Anit Mukherjee, and Kyle Navis}

\section{Abstract}

India is at the forefront of the use of digital technology to transform the way in which citizens interact with states. This paper provides a picture of the perceived impact of digitization reforms in Rajasthan, based on a survey of beneficiaries of several benefit programs. We find that, on balance, the reforms appear to have improved perceptions of service delivery despite some difficulties during the digitization process and the possibility — which we cannot fully assess with our datathat there could have been some degree of exclusion. The proportion of people preferring the new systems, at 40-60 percent, far exceeded the proportion who expressed a preference for the old system (5-12 percent). In the case of food and cooking gas subsidy reforms, the reason for the preference is relatively clear-they considered that the new systems gave them greater control over their entitlements and reduced the ability of others to claim their benefits or divert them. The main problems arise from biometric authentication. Shifting pensions from postal delivery to bank deposits is overwhelmingly supported, partly because of better regularity. Reforms in Rajasthan also had two cross-cutting goals: financial inclusion and women's empowerment. Our survey confirms that virtually all respondents have bank accounts, often two or more per family, as do all heads of household who are officially mandated to be women. Two thirds of these women had not owned bank accounts before the reforms. Mobiles emerge, however, as a male preserve. This suggests a further frontier for policies and programs to shift India towards a digital society-ensuring that all people have the capacity to access and to use digital technology.

JEL: H10, H11, O10, 030, 031, 035, 038
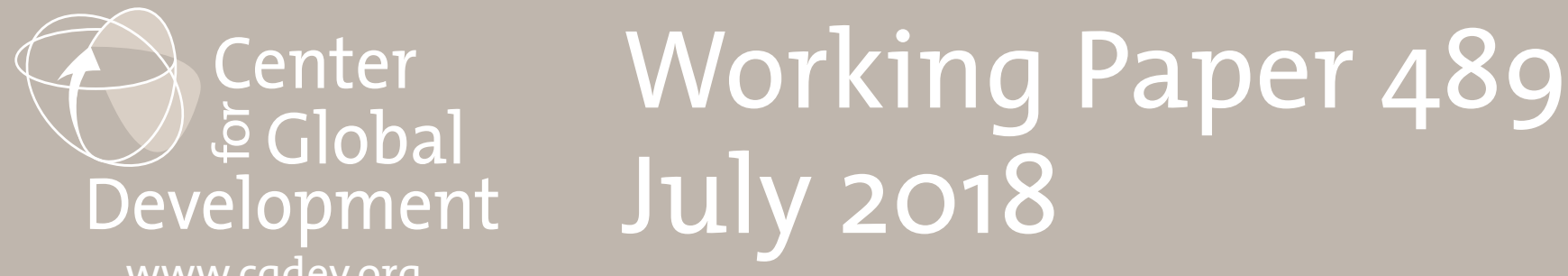


\title{
Digital Governance in Developing Countries: Beneficiary Experience and Perceptions of System Reform in Rajasthan, India
}

\author{
Alan Gelb \\ Center for Global Development \\ Anit Mukherjee \\ Center for Global Development \\ Kyle Navis \\ Center for Global Development
}

We thank MicroSave for their collaboration, especially for their support on the household survey and preliminary analysis.

The Center for Global Development is grateful for contributions from the Bill \& Melinda Gates Foundation in support of this work.

Alan Gelb, Anit Mukherjee, and Kyle Navis, 2018. "Digital Governance in Developing Countries: Beneficiary Experience and Perceptions of System Reform in Rajasthan, India." CGD Working Paper 489. Washington, DC: Center for Global Development. https://www.cgdev.org/publication/digital-governance-developing-countries-beneficiaryexperience-and-perceptions-system

The data and replication files for this paper are available here: https://www.cgdev.org/ sites/default/files/digital-governance-developing-countries-rajasthan-code.zip. More information on CGD's research data and code disclosure policy can be found here: www. cgdev.org/page/research-data-and-code-disclosure.

Center for Global Development 2055 L Street NW Washington, DC 20036

(f) 202.416 .4050

www.cgdev.org
The Center for Global Development works to reduce global poverty and improve lives through innovative economic research that drives better policy and practice by the world's top decision makers. Use and dissemination of this working paper is encouraged; however, reproduced copies may not be used for commercial purposes. Further usage is permitted under the terms of the Creative Commons License.

The views expressed in CGD Working Papers are those of the authors and should not be attributed to the board of directors, funders of the Center for Global Development, or the authors' respective organizations. 


\section{Contents}

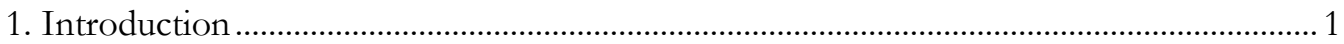

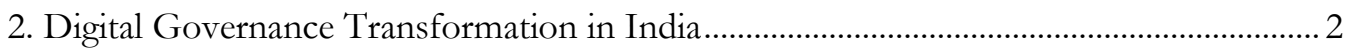

3. Rajasthan's Digital Governance Reforms: Survey Design and Data Collection................ 4

3.1 The Bhamashah Program: The Opportunity and Challenge for Research.................. 4

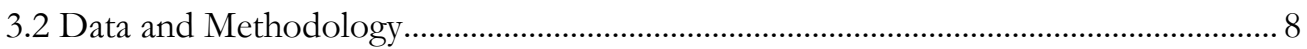

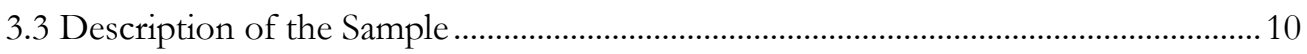

4. Perceptions of Service Quality by Program ....................................................................... 12

4.1 PDS - Direct Biometric Authentication for In-Kind Delivery ………………...........12

4.2 PAHAL: From In-Kind Subsidies to Direct Benefit Transfer for Cooking

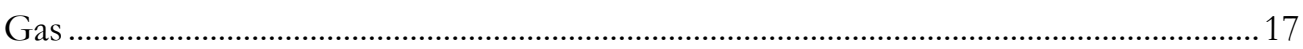

4.3 Social Pensions: From Postal Delivery to Direct Benefit Transfer into

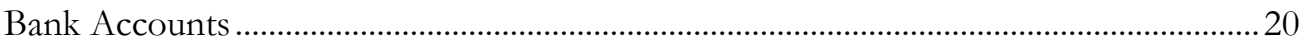

4.4 Financial Inclusion and Women's Empowerment: Have Reforms Had

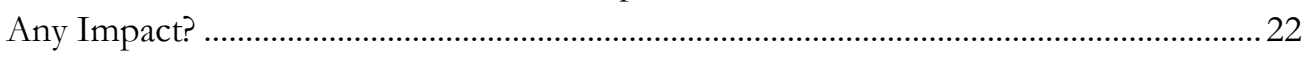

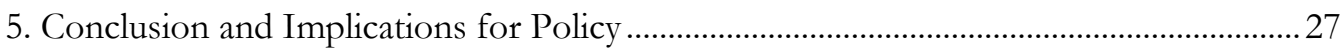

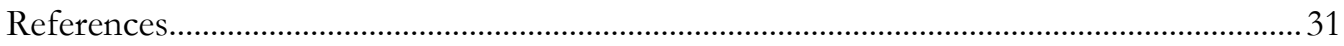

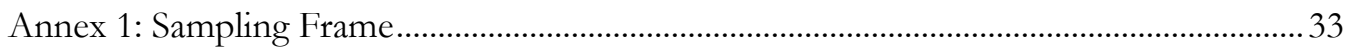




\section{Introduction}

Digital technologies are transforming the way in which citizens interact with states across the world. Previous systems which, especially in developing countries, were often personalized and operated at the communal or local level, are being superseded by new, more remote, delivery mechanisms as digital technology, in particular, for identification and payments, is engaged to reform public service delivery. The costly, and sometimes difficult, changes in administrative processes and delivery mechanisms are motivated by the ultimate objective of making governments more inclusive, efficient and accountable. The success of the reform process, therefore, depends critically on whether the delivery of public services have, or have not, improved along these three dimensions (Gelb \& Diofasi Metz, 2018; Atansah et.al., 2017).

Governments face complex challenges as they expand the use of digital technology in public services. They have to address issues of identification, targeting of beneficiaries and delivery mechanisms in a coherent way. Previously disparate data systems, sometimes with

conflicting information, must be integrated, while the inevitable date entry errors will need to be resolved. Even with the best communications efforts, many people will have limited understanding of the new systems. Some will not be able to use them effectively, requiring protocols for managing exceptions and speedy dispute resolution. All these challenges, and many others, make it even more important that the new systems, once bedded down, perform better than the old ones. This, in turn, makes it even more important to be clear on the problems - how serious are they, and how will digitization solve them?

India is one of the countries at the forefront of this transformation, bringing together three key technology-based pillars_-digital ID, financial inclusion and mobile coverage-to

reform systems of governance and improve state capacity. Full use of digital systems requires that people can be authenticated digitally and, with nearly 1.2 billion registrations, the Aadhaar biometric ID program has achieved almost universal enrolment. It is now being used, with other digital applications, to reshape large scale public programs such as food rations and fertilizer distribution, as well as the delivery of government payments such as pensions and scholarships. It is also a key component in energy subsidy reform, especially the move from in-kind subsidies to financial transfers for household purchases of LPG cooking gas (Mittal et.al., 2017). While the LPG program is national, most of the other programs are implemented by states, and these are moving at different speeds and taking somewhat different approaches to reform.

India is therefore a veritable laboratory to understand the impact of digital governance at both the macro and micro levels.

India's reforms are widely debated, in particular the use of Aadhaar and Aadhaar based authentication, in public service delivery and financial inclusion (Khera, 2017; Abraham et.al., 2017). With only a few exceptions (notably Muralidharan et.al. 2016), the literature on the experience and perception of beneficiaries vis-à-vis digital governance reform is still largely anecdotal. This paper aims to narrow this information gap by investigating the digital delivery transformation in the Indian state of Rajasthan. Rajasthan is not the most digitally 
advanced state in India - that title reputedly goes to Andhra Pradesh (the site of our next piece of research) — but neither is it bringing up the rear. Started in 2014, the "Bhamashah" program seeks to create a digital platform for delivery of public services for all residents of the state who receive benefits financed by the state government. We investigate the perceived impact of this transformation in the system of delivery of public benefits, subsidies and transfers through a household survey. To put the scale of Rajasthan in perspective, its area and population compare with those of Germany.

The rest of the paper is organized as follows. Section 2 outlines the background and context of India's digital governance reform. The approach of the study and design of the data collection is described in Section 3. In Section 4, we present the survey results on the experience and perceptions of beneficiaries of three large scale government programs, and consider the impact of reforms on financial inclusion and women's empowerment. Section 5 concludes with a summary of findings and policy implications of the study.

Indian states vary widely, in terms of their demographic, cultural and economic characteristics, and there is no guarantee that the conclusions of the study carry over to other contexts, even if they are reasonably accurate for Rajasthan. Moreover, the impact of any reform depends crucially on the nature and scale of the previous problems - the better the previous system was managed, the smaller are the potential gains from reform. For example, biometric deduplication of Pakistan's voter rolls in 2015 resulted in the de-listing of almost 40 percent of registered voters as duplicates and fakes, but this would not be expected from a similar effort in an established democracy. However, the approach taken in the survey has been to ask respondents to respond to questions on the strengths and weaknesses of the previous and the new systems as well as indicating which they preferred. This provides an opportunity to understand how the systems operated, at least from their perspectives. The answers may therefore convey some useful information for other cases considering similar reforms.

\section{Digital Governance Transformation in India}

Digital governance reform in India rests on three pillars popularly known as the "JAM trinity" (Government of India, 2016). This includes (i) the Jan Dhan program, the government's financial inclusion mission to increase access to bank accounts, (ii) the biometric ID Aadhaar, and (iii) mobile phones. From mid-2015, the financial inclusion program known as Jan Dhan Yojana (JDY) has opened nearly 311 million bank accounts, helping India achieve 80 percent coverage of those older than 15 years in 2017 compared to only 53 percent in 2014 (Demirgüç-Kunt et. al., 2018,). Following a nationwide rollout in 2011, the Aadhaar program has registered nearly 1.2 billion individuals on its biometric database, achieving almost universal coverage in just over five years. Finally, mobile phone subscriptions increased from 17 per 100 inhabitants in 2007 to 85 in 2016, achieving almost universal access within a decade (International Telecommunications Union, 2018). The relatively low cost of data-enabled value added services is providing an opportunity to integrate mobile services into the overall digital governance framework, especially for government-to-people (G2P) payments and subsidies. 
Building on these three different, though related, platforms, both federal and state governments have undertaken large-scale restructuring of the subsidies and transfers under their jurisdiction. In social pensions and other cash-based programs, payments to beneficiaries are now sent directly to their Aadhaar linked bank accounts through the Direct Benefit Transfer (DBT) mechanism. For LPG cooking gas, rather than mandate low prices for cylinders sold to households, the government now delivers the subsidy component directly to bank accounts of eligible consumers who pay the market price for the cylinder. This is effectively a voucher-type system. Finally, for food rations through the public distribution system (PDS), the federal government mandated the use of biometric authentication at Fair Price Shops (FPS), the point of distribution, with the objective of reducing leakage and diversion that was reputed to be endemic in the previous system. Digital technology is therefore being used in different ways across a spectrum of delivery mechanisms - cash, voucher, and in-kind.

These changes have been implemented in a relatively short period of time. In PDS for example, under the old system, families were entitled to receive subsidized foodgrains if they possessed a "ration card" which contained details of its individual members. Similarly, households received subsidized cooking gas cylinders if they were duly registered with stateowned oil marketing companies. The transactions were recorded in physical booklets that were issued to the beneficiaries of individual schemes. Beneficiary lists were maintained in databases managed by implementing departments and agencies of both the federal and state governments. These lists were widely believed to contain duplicate entries or non-existent beneficiaries, leading to widespread corruption and leakage in the distribution of government subsidies (Overback 2016; Dutta and Ramaswami 2011; Khera 2011).

In an attempt to remove the anomalies in the delivery of public subsidies, the new system has progressively incorporated digital technology for identification of beneficiaries and keeping record of transactions. For the distribution of PDS foodgrains, households in Rajasthan were mandated to re-register their ration cards in a digital format during the Bhamashah registration process. In addition, they also had to provide Aadhaar numbers of all the individual members which enabled them to biometrically authenticate at the FPS and collect their food rations. The list of subscribers of LPG cooking gas was initially deduplicated by matching names and addresses, and genuine subscribers were assigned a unique beneficiary number or LPG ID. Aadhaar was made mandatory for new cooking gas connections while existing consumers were encouraged to link their LPG ID with Aadhaar. (Mittal et.al. 2017). All DBT programs, including social pensions, required beneficiaries to provide an active bank account and a mobile number, items that many of them did not have before. The digital transformation therefore is not only in government systems and processes, but also for people to adapt to this new digital governance architecture. ${ }^{1}$

\footnotetext{
1 This can be quite challenging; for example, for an illiterate population accustomed to identifying banknotes by color and size to adapt to digital money: http://www.bbc.com/capital/story/20140904-more-to-money-thanmeets-the-eye?icid $=$ cap.tvl.sto.cross-site-series.bc.life-in-color_week2
} 
The reforms have been quite controversial and a subject of much debate in academic and policy circles, not only in India but globally. In addition to concerns over privacy and data protection, questions have been raised over the utility and efficacy of implementing Aadhaar authentication to in large government programs (Khera, 2017; Dreze et.al., 2017). There has also been a hot debate on the fiscal savings from Aadhaar-enabled programs, with the government offering substantial estimates and others disputing them (George \& Subramanian, 2015; Comptroller and Auditor General of India, 2016). Several issues remain unresolved, not least due to the unavailability of systematic data on the impact of the reforms on actual beneficiaries of the program.

Leaving aside the question of fiscal savings, the challenge is to improve the quality of delivery of services through digital reforms without excluding legitimate beneficiaries. While one common theme is help remove duplicate, non-existent or inactive entries from the list of beneficiaries across programs, there were also specific issues that the new digital infrastructure intended to address. In PDS and PAHAL for example, diversion of subsidized rations and cylinders and variability in the timing of their distribution was believed to be pervasive in the old system. Pension delivery through the postal system was said to be unreliable, and it was asserted that delivery agents sometimes charged "fees" for their service. On the other hand, it is also possible that the new systems could be exclusionary or cause inconvenience to beneficiaries, due to problems in biometric authentication for PDS rations, or connectivity failures. For PAHAL or pensions, where benefits are transferred directly to bank accounts, limited access to banks and the time-cost of withdrawing money could cause additional hardship under the new digital system.

Evidence on the impact of these reforms on the quality of service delivery is scarce, while that on exclusion is mostly anecdotal. This paper aims to narrow this gap in the literature by empirically testing hypotheses on the functioning of the previous and the new systems using a new dataset of beneficiaries who have been impacted by the reforms in Rajasthan, and covering both urban and rural areas of the state.

\section{Rajasthan's Digital Governance Reforms: Survey Design and Data Collection}

\subsection{The Bhamashah Program: The Opportunity and Challenge for Research $^{2}$}

Bhamashah is, as far as we know, the first nuclear-family-level identity system in India. It was first conceptualized by the Rajasthan government in the year 2008 and rolled out at scale from 2014 onwards. The Bhamashah scheme registers each family with a unique family ID number and issues a family card which lists individual members along with their Aadhaar numbers. It also captures other socio-economic and demographic characteristics during the

\footnotetext{
2 Authors are grateful to Arshi Aadil of MicroSave for her inputs into this section
} 
registration process, thereby creating a comprehensive database for residents of Rajasthan following the principle of "one family, one identity."

As in a number of other digital reforms, implementation preceded legislation. The Rajasthan government gave legal backing to Bhamashah program through "The Rajasthan Bhamashah (Direct Transfer of Public Welfare Benefits and Delivery of Services) Act of 2017.”

Following the passage of the legislation, the Bhamashah family identification number has been made mandatory for beneficiaries to avail their entitlements from over 150 schemes that are wholly or partially funded by the Government of Rajasthan. ${ }^{3}$ Families who do not receive any public benefit are not required to register in the program. However, with more services being included under the ambit of the Bhamashah program, the proportion of households registered is likely to increase over time.

The process of registration is depicted in Figure 1. Under the scheme, a centralized data warehouse called the Bhamashah Resident Data Hub (BRDH) maintains the family level information, determines eligibility for public benefits and keeps a digital record of delivery of entitlements for both individuals and families. More than 56 million people 80 percent of the Rajasthan population as per census 2011) and 15 million households (83 percent of estimated total households) had been enrolled under the Bhamashah scheme by December 2017 Those that have not enrolled include those who may have chosen not to do so since do not receive any of the government benefits listed under Bhamashah as well as segments of the population who may have been left out during the registration, such as migrants and those residing in remote areas of the state. On the delivery side, since 2014 nearly 400 million transactions had been routed through the Bhamashah platform transferring nearly $\$ 2.9$ billion in government payments, and enabling them to be tracked down to the individual beneficiary level. ${ }^{4}$

Figure 1. Bhamashah enrolment process

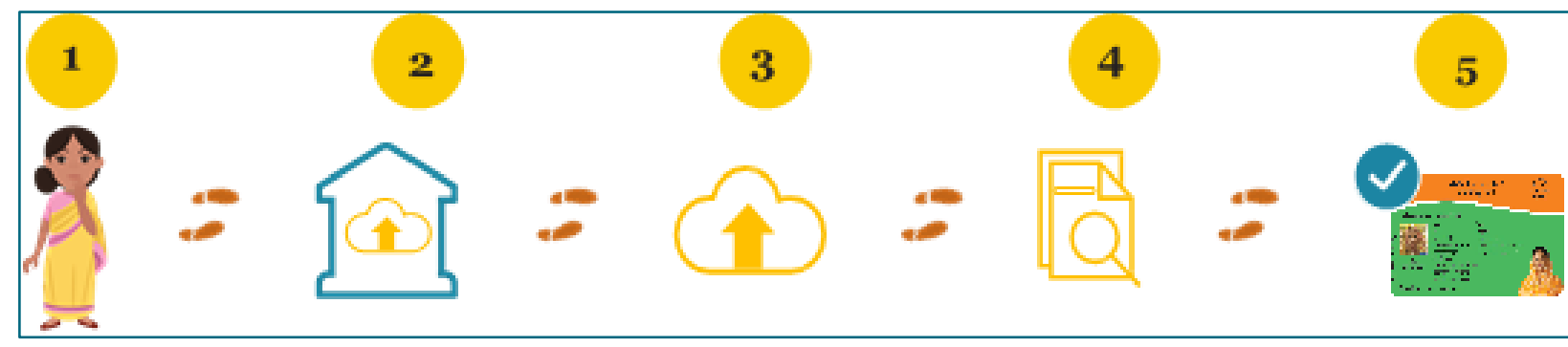
Beneficiary
Government
camp or
private e-
Forms/documents
Verification conducted at block and state
Bhamashah Mitra are uploaded online
level; entered into the
BRDH database
Bhamashah family card generated and dispatched to beneficiaries

\footnotetext{
${ }^{3} \mathrm{~A}$ full list of schemes and current status is available from the official Bhamashah website: http://bhamashah.rajasthan.gov.in/content/raj/bhamashah/en/home.html

${ }^{4}$ http://bhamashah.rajasthan.gov.in/content/raj/bhamashah/en/home.html (Accessed April 26, 2018)
} 
The design of the Bhamashah program is based on a "whole of government approach" under the direct supervision of the Chief Minister's office and therefore enjoys a high level of political support. On the implementation side, it brings together the three technology platforms-ID (Aadhaar), banking and the mobile system. Each member of the household is listed on the family card with their respective Aadhaar numbers. The bank account of the designated head of household is registered on the family card and all cash transfers are delivered into this account. Finally, the family card is linked with one active mobile number, thereby bringing all the three platforms together in an integrated fashion. Moreover, against the backdrop of a strongly patriarchal society, the program mandates that the designated head of household be a woman. It thus aims to promote women's empowerment by making them the primary recipient of all transfers from the government, both cash and in-kind. This is seen as an especially important spillover from the move towards digital governance in the state. While it cannot realistically be expected to revolutionize gender norms immediately, it is hoped that its impact on these and on women's agency, will be visible in the years to come.

Rajasthan's digital governance reform represents both an opportunity and a challenge for efforts to understand the perceived impact of digital service delivery. Most existing studies consider the impact of digital reforms in the context of a particular scheme or sector, such as the LPG program or the PDS (Mittal et.al, 2017; Dreze et.al., 2017). In contrast, Bhamashah provides an opportunity to look at an effort to reorganize and consolidate a number of disparate programs around the theme of a nuclear family. ${ }^{5}$ Such a step could be the precursor, for example, to more extensive consolidation, even to the point of a family-based universal benefit program. But Bhamashah is not itself a major benefit program in the sense of pensions or the PDS. The only two benefits specifically related to it are an upfront registration payment of Rs. 2000 to BPL families, and premium support for the BSBY health insurance program. Both are discussed in detail in a separate report ${ }^{6}$ but are not the main benefit programs considered in this paper.

The challenge arises because the experience of consolidation into Bhamashah-at the same time as the PDS, pension and other programs were being digitized and reformed — will inevitably influence people's views of the reforms as a whole and, by extension, views on the digitization of the major individual programs. Those not eligible for benefits had no reason to enroll, although the program is now being extended as a requirement for other services, such as state driving licenses. The motivation for families to enroll varied. The most important reason was the threat of denial of benefits, along with the demonstration effect of mass enrollment drives conducted by the state government. Nearly 70 percent of the survey respondents cited these as the main reason for Bhamashah registration. In addition, nearly 60 percent reported that the monetary incentive of Rs. 2000 influenced their decision to

\footnotetext{
${ }^{5}$ We use the words family and household interchangeably and colloquially refer to the head of the family as the "Bhamashah head of household" in subsequent discussion.

${ }^{6}$ http://www.microsave.net/files/pdf/171212 Household Perception Impact of Bhamashah Digital Governance Reforms in Rajasthan.pdf
} 
enroll in the program — even though only 40 percent of eligible beneficiaries reported having received the amount.

However, the processes of digitization and restructuring benefits into the Bamashah program were not smooth. As described in greater detail elsewhere, they created uncertainty and inconvenience for many people and may also have led to some exclusion of legitimate beneficiaries (MicroSave, 2017). While the government made significant effort to include as many families as possible through local registration camps and enrolment agents (known as E-Mitra-s), it is possible that some categories were not fully covered, especially migrants or those who could not prove residency as required to access state programs. Since our survey is designed to capture the experience and perception of beneficiaries who have enrolled in Bhamashah, we are not able to fully understand the possible extent of exclusion, or how it does, or does not, relate to the digitization process.

Most households found enrollment into Bamashah relatively easy, but digitization errors, mostly in the form of manual data entry errors during enrollment, caused inconvenience to exisiting beneficiaries. As many as 10 percent of households needed to visit E-mitras-local businesses that provided assistance to navigate the new system-to rectify mistakes on their Bamashah cards. While enrollment was supposed to be free, 19 percent of the households reported having to pay E-mitras at some point during Bamashah registration. Data errors were a serious concern —an immediate repercussion of incorrect data, such as faulty birth dates, could be the reduction or halting of pension benefits. As noted in Section 4.3 below, 5 percent of pensioners reported that their pensions were stopped temporarily during the changeover to the direct transfer system. When this happened, those affected sometimes did not know how to rectify the problem.

Perhaps most significantly, the process of digitization of NFSA beneficiaries sowed confusion and anxiety. Starting in 2012, local workers and officials had assisted the government to digitize ration cards. In the process, the number of eligible BPL beneficiaries had reached 53 million as against the target number of 44.6 million. The government then conducted a large-scale verification exercise in parallel with the Bamashah registration process and eliminated approximately 9 million households. The combination of errors and the influence of local politics during the verification process probably resulted in significant exclusion of legitimate beneficiaries, or at least of people who believed themselves to be eligible for programs.

One lesson from Rajasthan's experience is therefore that digitization brings many challenges, including the problem posed by inconsistencies across different lists of beneficiary data. Even if the reformed systems are expected to work more smoothly than those they replace, the transition from old to new system needs to be well managed, including the resolution of grievances, if the reform is not to be viewed in a negative way.

We have tried in this study to distinguish between the "Bhamashah experience" and other transitional factors that may have colored opinions on the reforms and-our main focusexperience with the service delivery from digitized programs. But we cannot be completely 
certain that opinions on these different aspects of the reform process can be reported in a totally separated manner.

\subsection{Data and Methodology}

As described in the previous section, the delivery of public services in India is undergoing rapid change with the implementation of the JAM framework-Jan Dhan (financial inclusion), Aadhaar and mobile. Different programs have designed the reforms in various ways, depending on their objectives and intended outcomes. Delivery system reforms fall broadly into three categories: (i) biometrically authenticated physical uptake, or BAPU, as seen in in PDS and subsidized fertilizer delivery; (ii) cash transfers on proof-of-purchase as in the reform of cooking gas subsidies (a voucher-like mechanism); and (iii) direct benefit transfer (DBT) of social pensions and scholarships and other monetary payments from the government into beneficiary bank accounts. The two main goals of these reforms have been fiscal savings (which we do not consider in this paper) and improved delivery of transfers and subsidies to ultimate beneficiaries.

States have further innovated on these platforms and shaped program design and delivery mechanisms taking into account the situation on the ground. In addition to improving service delivery, the reforms in Rajasthan aimed for two further cross-cutting objectives: greater financial inclusion and the empowerment of women (Figure 2). With a focus on three major programs, this provides a framework of five major objectives to be investigated through the survey.

Figure 2. Objectives of Rajasthan's reforms

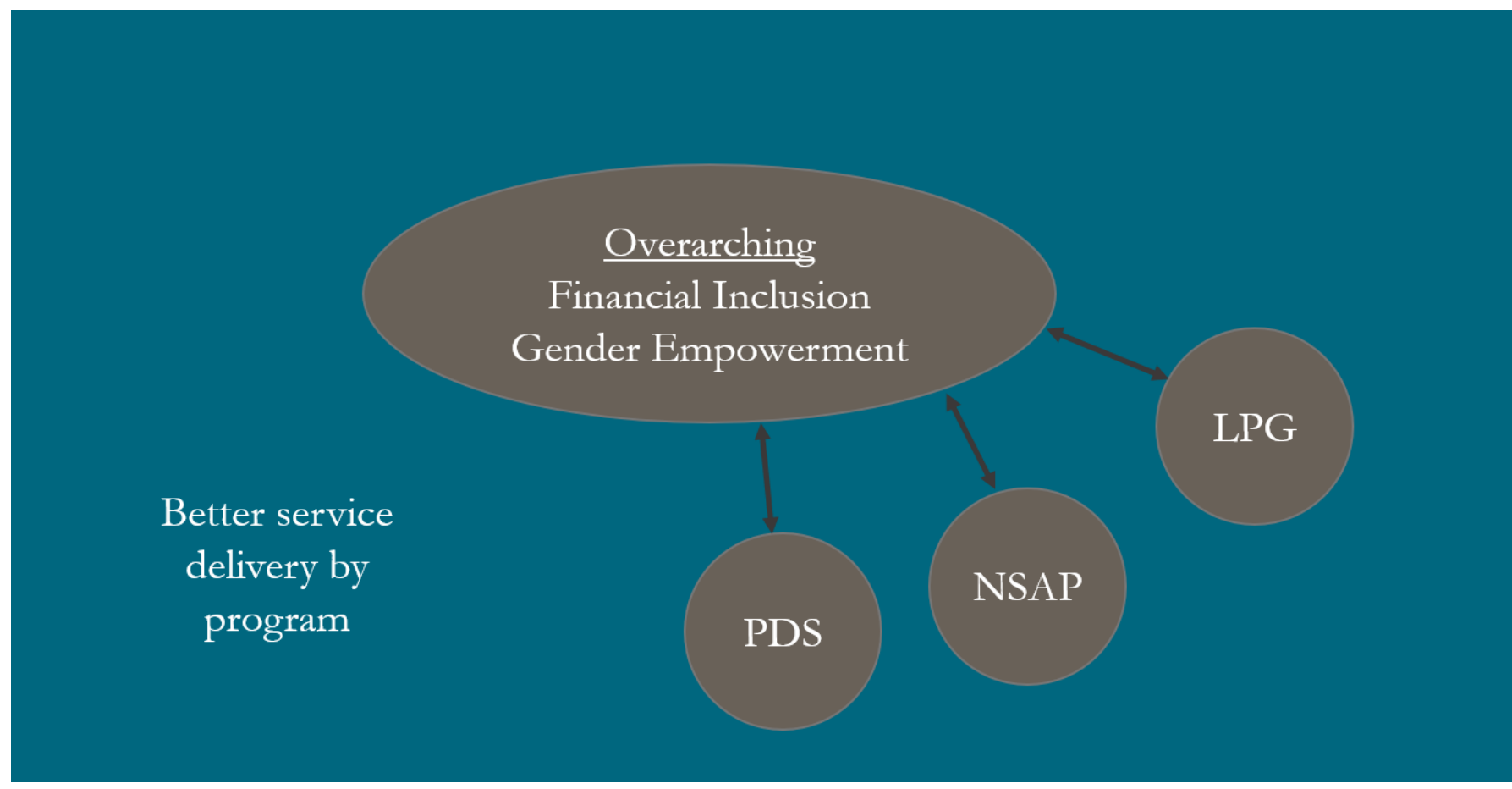


The field survey of beneficiaries of government programs was carried out between May and July, 2017. The sample included a total of 633 households spread across all seven administrative divisions of the state. We selected a representative district from in each division, two blocks (one each urban and rural) in each district and, within these, randomly selected villages and wards for enumeration, dividing the total sample for the district in proportion to its rural-urban population ratio. The geographical distribution of the survey is summarized in Figure 3. The full survey design is explained in Annex 1 and the full questionnaire available from the link below. ${ }^{7}$

Figure 3. District, block, and sample for Rajasthan survey

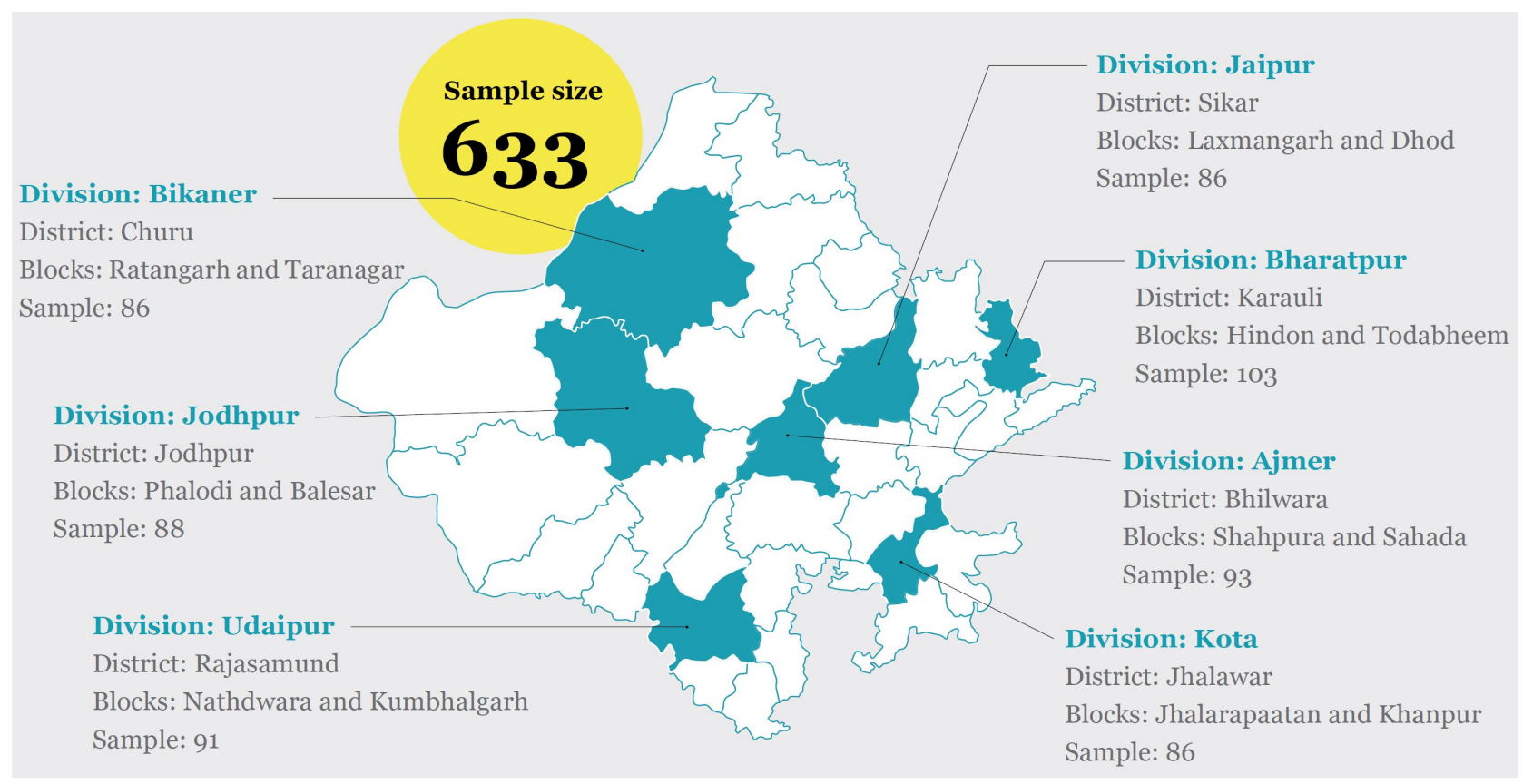

A detailed questionnaire, administered to the selected families, gathered information on the socio-economic status of the family, their experience with the Bhamashah enrolment process and their perception of the changes in the modes of program delivery. It was emphasized at the outset that this was an independent survey without any involvement of the government (no officials accompanied the survey or monitored results) and respondents were encouraged to provide their honest assessment without the threat of any repercussions for their expressed opinions. The questionnaire was structured to gather scheme-wise information from beneficiaries with the objective of distinguishing between the various delivery mechanisms and modes of technology usage, including for authentication, bank transfers and mobile phones. In addition, we included questions on the use of banking services and mobile technology, with special attention to the role of women. This allows us to analyze the data from the lens of women's economic empowerment through design of the

\footnotetext{
${ }^{7}$ See the full questionaire here: https://www.cgdev.org/sites/default/files/Rajasthan_Bhamashah_Questionnaire Final.pdf
} 
programs on one hand and the extent of digital empowerment through use of mobile phones on the other, as well as financial inclusion.

The structure of the questionnaire followed some simple principles. First, we tried to be neutral in the construction of questions-asking for a view on whether the quality of service delivery through the new systems was seen to be better, the same, or worse than that of the previous arrangements. Since the changes are relatively recent, the possibility of recall bias is low. Second, respondents were invited to provide the reasons for their opinions. The response options for these questions included choices related to several of the hypotheses about the workings of the old and the new systems noted previously. For example, it is sometimes argued that shifting from pensions hand-delivered by postal officials to direct pension deposits into a bank account will improve the regularity or completeness of payment, but improvement is only possible if these had been problematic in the previous system. On the other hand, the most likely problem with the new direct deposit system is the time and effort needed to cash out the proceeds at a possibly distant bank branch. Including such considerations in response options provides a way to test hypotheses about the perceived strengths and weaknesses of both the previous and the new systems.

\subsection{Description of the Sample}

In terms of social and economic characteristics, the sample appears to represent a broad cross-section of the state population. Respondents were divided about equally between the rural and urban sectors. Since the Bhamashah mandate has designated females as heads of household, we oversampled women; nearly two-thirds of our respondents were the Bhamashah head of household. This is a significant number given the cultural constraints of interviewing women in a private setting in Rajasthan.

In terms of economic characteristics, 40 percent of respondents reported below poverty line (BPL) status, in line with overall guidelines. Just over 40 percent of all households surveyed (including urban) did not own any agricultural land. Another 30 percent reported having less than half an acre of land and therefore can be classified as marginal farmers. In terms of reported income, nearly 10 percent of households reported receiving less than Rs.2000 per month ( $\$ 30$ at current exchange rate); these we termed "destitute" to distinguish them from the broader BPL group. Just over 80 percent of households in our sample earned between Rs.2000 and Rs.10,000 a month (\$150) while around 7 percent were above this threshold. This distribution of income appears to reflects the reality on the ground, where there are still many very poor families and few high earners. There is a reasonable degree of correlation between these various measures of social and economic status, as well as between them and other indicators, such as possession of a mobile phone. 
Table 1. Selective summary of the sample

\begin{tabular}{|c|c|c|c|}
\hline & & Frequency & Percent \\
\hline \multirow{2}{*}{ Location } & Urban & 310 & 49.0 \\
\hline & Rural & 323 & 51.0 \\
\hline \multirow{2}{*}{ Gender } & Male & 226 & 35.7 \\
\hline & Female & 407 & 64.3 \\
\hline \multirow{3}{*}{ Land ownership } & Do not own land & 262 & 41.4 \\
\hline & Less than 0.4 acre & 199 & 31.4 \\
\hline & More than 0.4 acre & 172 & 27.2 \\
\hline \multirow{4}{*}{ Monthly family income } & $<$ INR 2000 & 63 & 10.0 \\
\hline & INR 2000-INR 5000 & 261 & 41.2 \\
\hline & INR 5000-INR 10000 & 263 & 41.6 \\
\hline & INR 10000 and over & 46 & 7.3 \\
\hline \multirow{2}{*}{ BPL Card status } & Yes & 256 & 40.4 \\
\hline & No & 377 & 59.6 \\
\hline \multirow{2}{*}{$\begin{array}{c}\text { Family has at least one } \\
\text { mobile phone? }\end{array}$} & Yes & 594 & 93.8 \\
\hline & No & 39 & 6.2 \\
\hline \multirow{5}{*}{$\begin{array}{l}\text { How many bank accounts } \\
\text { does the family have? }\end{array}$} & 0 & 1 & 0.2 \\
\hline & 1 & 94 & 14.9 \\
\hline & 2 & 333 & 52.6 \\
\hline & 3 & 126 & 19.9 \\
\hline & 4 or more & 79 & 12.4 \\
\hline
\end{tabular}

In terms of income-related indicators and APL/BPL status, there is no overwhelming difference between urban and rural respondents. However, the districts from which the sample was drawn show a fair amount of heterogeneity. Income per head in Bhilwara, the richest district sampled, is roughly twice as high as in Churu, the poorest district. The sectoral composition of economic activity also differs across districts, with industry and commerce more dominant in the richer ones and agriculture more pronounced in the poorer.

In order to assess the experience and perception of changes in the mode of delivery of public services, these need to be received by a fair number of households. Out of 633 households, 535 received PDS ( 85 percent), 413 received the PAHAL cooking gas subsidy (65 percent) and 126 received old-age pensions ( 20 percent). Almost all households surveyed received at least one technology-enabled benefit and some received several. This does not necessarily imply that families are receiving benefits when they should not be; for example, APL families are also eligible for PDS rations although their ration allocations are substantially lower than those of BPL families.

Other notable features of the sample are the degree of Aadhaar coverage and financial inclusion. Aadhaar was universal, as might have been expected since these were program 
beneficiaries. Every household had at least one bank account and nearly 95 percent of households owned at least one mobile phone (Table 1). As explained below, this degree of financial inclusion had not prevailed prior to the reforms - it points to the considerable success of the rollout of both biometric ID and financial inclusion initiatives within a short period of time. As bank and mobile linkage with Aadhaar becomes universal, the government will be in a position to use this framework for other schemes, such as fertilizer and rural credit. Our survey results are a pointer to whether the existing mechanisms are working as expected and what can be done to make them better from both the system and beneficiary standpoint.

\section{Perceptions of Service Quality by Program}

In each of the three different classes of programs that we investigated, namely, in-kind distribution (PDS), vouchers (PAHAL) and cash transfers (social pensions), between 40 and 60 percent of beneficiaries had an unambiguously positive perception of the reforms (Figure 4). Twelve percent of PDS beneficiaries, and only a few percent of cooking gas subsidy voucher (PAHAL) and social pensions reported that the new system was worse than the previous one. We consider each of the programs in more detail below.

Figure 4. Beneficiary perception of technology enabled delivery of services

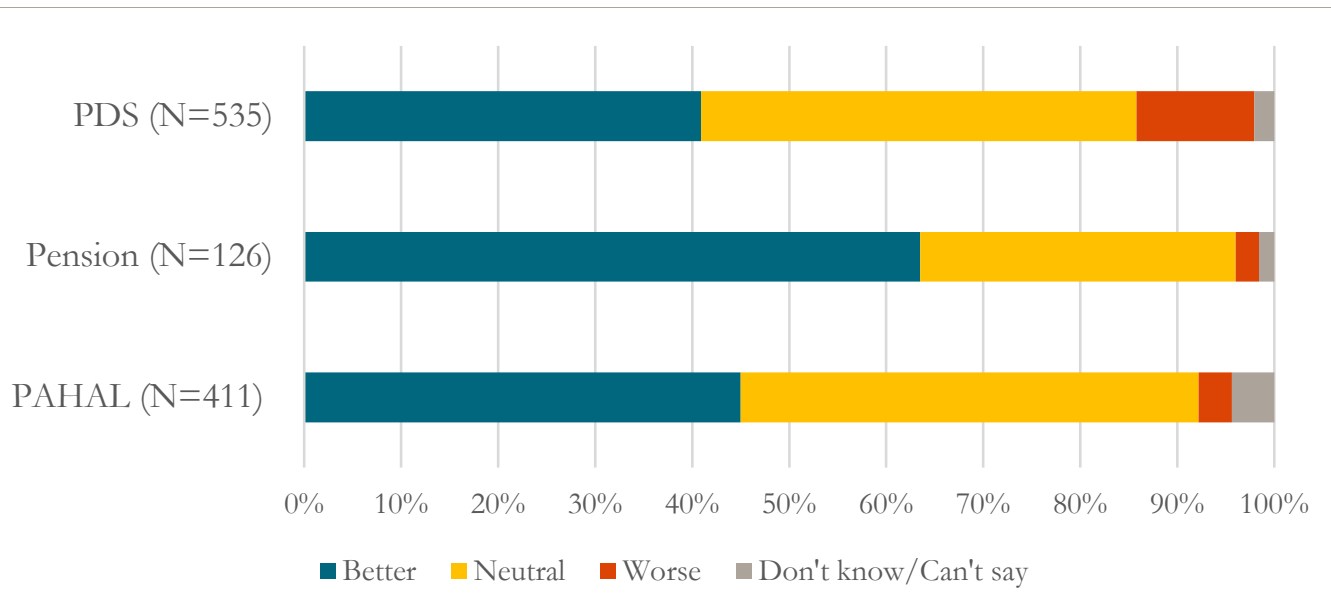

\subsection{PDS - Direct Biometric Authentication for In-Kind Delivery}

\subsubsection{Process of Digitization}

In the recent past Rajasthan's PDS system has undergone several significant changes to its delivery mechanism. In 2012, the government mandated the digitization of ration cards to weed out false and duplicate beneficiaries. By all accounts, however, the process did not go as planned, with complaints of mishandling of data and erroneous entries creating significant inconvenience for the beneficiaries. Following the passage of the National Food Security Act (NFSA) in 2013, there was a further effort to reclassify families based on BPL or APL status in accordance with the new financing formula announced by the federal government. Our 
qualitative focus group discussions captured a sense of frustration on the part of the beneficiaries with the frequency of administrative directives and a lack of transparency in the revision of the eligibility list for PDS.

Bhamashah registration-including linking ration cards to Aadhaar, bank account and mobile numbers - was yet another process that the beneficiaries needed to go through to obtain their PDS quota. In contrast to previous attempts to reform the PDS, the new system requires beneficiaries to biometrically authenticate themselves at the FPS and directly interact with the new technology- enabled framework. At the same time, dealer margins were increased several-fold from their previously very low levels, to compensate for the smaller degree of diversion expected from the new system. Margins were increased to roughly 5

percent of the market prices of the products. We understood that without this increase many dealers would have ceased business.

\subsubsection{Beneficiary perception of digitization}

As noted, our survey finds that just over 40 percent of PDS beneficiaries prefer the new system better than the old one while 12 percent find it worse. Why do they express these views? Almost all of those who preferred the new system cited increased agency, that under the new system no-one was able to take their rations on their behalf (Figure 5). This does not, of course, prove that rations were actually diverted under the old system (we did not actually measure how much they received), but it indicates substantial concern that they were not reaching the entitled beneficiaries. The second most frequent reason cited was satisfaction with using new technology. Despite frustrations with the new system (as further discussed below) this suggests a good deal of support for digital governance more broadly.

Interviews with PDS dealers provide some anecdotal support to the proposition that diversion had been reduced. When faced with the question of whether the digitization of the system, combined with higher margins, had changed the social or economic position of dealers, one responded: "Before, in the old system, I was considered a thief when I stole, and also when I did not steal. Under the new system, I am considered more as a businessman."

What about the 65 respondents who say the new system is worse than the previous one? Most of their problems appear to relate to the biometric authentication process. Responses suggest that barely a quarter of the beneficiaries are authenticated at the first attempt although 96 percent said that they were usually authenticated in four attempts or less (Table 2). Only 6 respondents out of 535 stated that fingerprint authentication "never works." 


\section{Figure 5. Reasons for better perception of new PDS system}

No one takes my ration on my behalf

Enjoy using technology

Pay less money than before

Receive more quantity

Awareness of entitlement

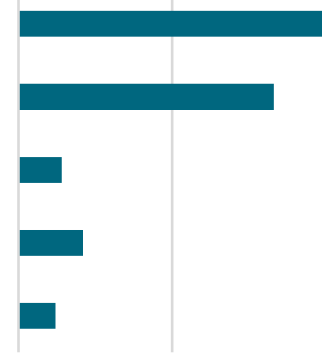

0

50

100

150

200

219 respondents; Multiple responses possible

Table 2. Distribution of the number of attempts required for fingerprint authentication

\begin{tabular}{|r|c|c|c|c|}
\hline $\begin{array}{c}\text { On average, how many attempts } \\
\text { does it take for fingerprint } \\
\text { authentication? }\end{array}$ & Number & $\begin{array}{c}\text { Percentage } \\
\text { of Total }\end{array}$ & $\begin{array}{c}\text { Attempt } \\
\text { Success } \\
\text { Rate }\end{array}$ & $\begin{array}{c}\text { Cumulative } \\
\text { Percentage }\end{array}$ \\
\hline Once & 127 & 23.74 & $23.74 \%$ & 23.74 \\
Twice & 253 & 47.29 & $62.01 \%$ & 71.03 \\
3 or 4 times & 133 & 24.86 & $85.81 \%$ & 95.89 \\
5 or more times & 16 & 2.99 & $72.73 \%$ & 98.88 \\
Never works & 6 & 1.12 & --- & 100 \\
Total & 535 & 100 & & \\
\hline
\end{tabular}

\subsubsection{Beneficiary Experience of Digitization}

Ease of authentication is a significant predictor of satisfaction. Ordered logit regressions show that people who report the need for three to four attempts to authenticate are 17 percent more likely say the new system is worse than those who report succeeding in only one or two attempts. ${ }^{8}$

\footnotetext{
8 The econometric analysis referenced in this paper utilizes univariate ordered logistic regression models to compute linear predictions, and then report marginal probabilities for given ordinal categorical outcome variables (Long \& Freese, 1990). We only report statistically significant (at $\alpha=0.05$ ) marginal probabilities and apply a Brant (1990) test as a robustness check to ensure that the proportional odds assumption is met, and do not report any linear prediction which fails the Brant test.
} 
What would happen if fingerprint authentication failed to work? A majority (49) responded to the question by saying that they would be "denied rations." As discussed further below, this does not always appear to mean that they would actually fail to receive rations, but at the least it points to considerable frustration over the time and effort required to get them. The other major reason for negative perceptions was the need to make multiple visits to the FPS due to connectivity problems. Both authentication and connectivity failures are credible concerns that need to be addressed if the new system is not to inconvenience, or even exclude, genuine beneficiaries.

Further insight comes from a more detailed look into responses to the question. (Table 3). Row 1 shows the responses from those who only reported having been "denied ration." The remaining rows show whether the person "denied ration" had recourse to any corrective action, including under an exception management protocol. Respondents were provided with multiple options, including returning another day or bringing someone else from the family to the FPS. Another possible choice was the use of an alternative authentication protocol, such as an OTP sent to a linked mobile number.

The results suggest that perceptions of "worse" are strongly associated with onerous processes that require extra time and effort, particularly the need for repeated visits to obtain rations. The option to use a mobile OTP does not seem to have been used frequently. However, not one of the four respondents who cited the use of the OTP rated the new system as worse, suggesting the need for a rapid exception-management protocols to be implemented when biometric authentication does not work.

Table 3. Authentication failures and perception of reforms

\begin{tabular}{|c|c|c|c|c|c|}
\hline \multirow{2}{*}{ Authentication failure experience } & \multicolumn{5}{|c|}{$\begin{array}{l}\text { Perception of Aadhaar authentication for PDS } \\
\text { (number of respondents) }\end{array}$} \\
\hline & Better & Neutral & Worse & $\begin{array}{l}\text { Don't } \\
\text { know }\end{array}$ & $\begin{array}{l}\text { Row } \\
\text { Total }\end{array}$ \\
\hline Denied ration (only) & 5 & 18 & 18 & 1 & 42 \\
\hline $\begin{array}{l}\text { Denied ration }+ \text { another family } \\
\text { member comes to take ration }\end{array}$ & - & 5 & 1 & - & 6 \\
\hline $\begin{array}{l}\text { Denied ration }+ \text { used mobile \& OTP } \\
\text { authentication }\end{array}$ & - & 2 & - & - & 2 \\
\hline $\begin{array}{l}\text { Denied ration }+ \text { need to visit again } \\
\text { next day/after some time }\end{array}$ & 1 & 5 & 13 & - & 19 \\
\hline $\begin{array}{l}\text { Denied ration }+ \text { need to visit again } \\
\text { next day/after some time }+ \text { another } \\
\text { family member comes to take ration }\end{array}$ & 4 & 4 & 2 & - & 10 \\
\hline $\begin{array}{l}\text { Denied ration }+ \text { need to visit again } \\
\text { next day/after some time }+ \text { another } \\
\text { family member comes to take ration } \\
+ \text { used mobile \& OTP } \\
\text { authentication }\end{array}$ & 1 & 2 & - & - & 3 \\
\hline
\end{tabular}


Whether the new systems cause eligible families to be denied rations due to authentication failures is a topic of much debate in India (Khera, 2017). Unfortunately, the framing of our question limits the information we can obtain from the answers. From Table 3, in response to the question of what happens if authentication fails, 82 out of 535 respondents stated that they would be "denied rations." However, there is no relationship between "denied" and the number of fingerprint authentications needed; many answer "denied" even when they say authentication works after one or two attempts. This suggests that some answered the question as a hypothetical "what if." Some who cite "denied" also consider that the new system is "better" than the old one and many consider it neither worse nor better (Table 4). Respondents could check several responses in addition to "denied," such as bring another family member or come back another day, suggesting that "denied" may, in some cases, have been interpreted as a temporary delay in obtaining rations. Nevertheless, there is a clear and significant relationship between "denied" and the view that the new system is worse, suggesting that the response does indeed, at the very least, reflect a negative experience for many.

Table 4. Opinion of new system when "denied rations" is the response

\begin{tabular}{|r|c|c|c|}
\hline \multicolumn{1}{|c|}{ Opinion } & $\begin{array}{c}\text { NOT } \\
\text { “denied } \\
\text { rations" }\end{array}$ & $\begin{array}{c}\text { "Denied } \\
\text { Rations" }\end{array}$ & Total \\
\hline Better & 208 & $\mathbf{1 1}$ & 219 \\
Neutral & 204 & 36 & 240 \\
Worse & 31 & $\mathbf{3 4}$ & 65 \\
Do not know as never received rations & 10 & 1 & 11 \\
Total & 453 & 82 & 535 \\
\hline
\end{tabular}

Have the reforms impacted differently on different social or economic groups? We had expected to find fingerprint authentication more difficult for the elderly, farmers and the poor, and also expected some systematic relationships between social and economic variables and views on service delivery. But there are not as many strong and consistent patterns as we had anticipated in our econometric analysis of the survey data. Authentication is reported as more difficult by rural respondents, especially those we classified as destitute, but BPL respondents as a whole are more likely to say that authentication is easy than APL respondents. Landowners, especially marginal ones with less than one acre, are less likely to say that the new system is better than those without land, but this result does not carry through to larger landowners. We find that authentication is harder for families without mobile phones, hinting at unfamiliarity with technology as one possible reason for less favorable perceptions. Indeed, Bhamashah heads of household who read messages and make mobile calls are more likely to like the new system better (Figure 6). This suggests a link between digital literacy and perception of the digital reforms, a noteworthy result also from a gender perspective. "Early adopters" who had enrolled in Aadhaar before it began to be used for PAHAL were less likely to cite a preference for new technology as a factor motivating their preference for the new PDS system. Moreover, counter to expectation, these early adopters were actually more likely to report difficulties with authentication. 
However, only some 20 percent of the total number of responses could be cross-classified in this way.

Figure 6. Opinion of the new PDS system by Bhamashah Head of Household mobile literacy

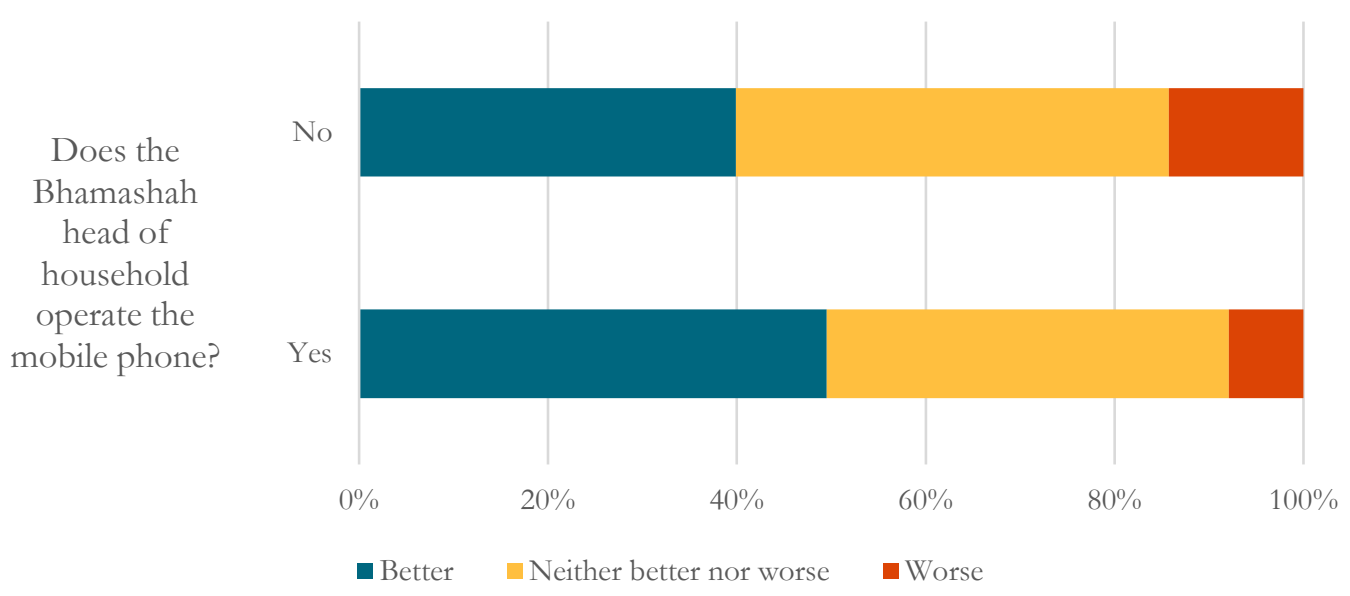

Our impression from the data is that experience is important in shaping attitudes to the reform and that there is considerable variation in experience that cuts across status and personal characteristics. This could reflect heterogeneity in experience across the different sampled communities, for example, a more or less skilled PDS fingerprint operator, although the limited size of our data set precludes statistical assessment of differences between sites. It could also be that the reference point for the reforms - experience under the old systemdiffers systematically across groups and individuals so that greater reported difficulties in navigating the new system do not necessarily translate into an assessment that the new system is worse than the old one. We return to this question when considering responses to the reform of the LPG and pension systems.

\subsection{PAHAL: From In-Kind Subsidies to Direct Benefit Transfer for Cooking Gas}

\subsubsection{Process of Digitization}

From 2013 onwards, India has undertaken a significant reform of its cooking gas subsidy program. The direct benefit transfer for LPG (DBTL), known as PAHAL, currently covers over 190 million beneficiaries and is considered the largest direct cash transfer program in the world. PAHAL is a federal government scheme managed by the Ministry of Petroleum and Natural Gas (MoPNG) and implemented by the three state-run oil marketing companies in charge of distribution of cooking gas to consumers.

The reform strategy is described in detail by Mittal, Gelb and Mukherjee 2017 and will only be re-capped briefly here. PAHAL imposed a cap of 12 subsidized cylinders per household per year and moved from subsidized to market pricing for domestic cylinders. The subsidy 
was provided in the form of a direct cash transfer to designated bank accounts. These had to be linked with a unique LPG ID, thereby creating a de-duplicated list of consumers. Aadhaar was not used for the first stage of de-duplication and was not mandatory for receiving the subsidy for existing consumers but new LPG connections are seeded with Aadhaar from inception. However, the policy has been to nudge all consumers to link their Aadhaar and active mobile numbers with the LPG database.

The objective of this direct benefit transfer (DBTL) approach was to eliminate the incentive for dealers to divert subsidized cylinders to the black market. Under the old system, this could be done without the knowledge of the consumers for whom the subsidies were intended. The reform also put in place an information portal through which consumers were able to monitor and track the status of deliveries initiated by them.

The Ujjwala program that followed on from PAHAL has provided nearly 30 million new cooking gas connections to rural women from mid-2016 onwards on a nationwide scale. The program requires them to open a bank account if they do not have one already and to link it with Aadhaar so that the subsidy amount can be transferred directly when they purchase a cylinder. For many rural women, this has been their first experience with both clean fuel and the formal banking system.

Our survey sought to capture the perception of the new mechanism and the challenges faced by beneficiaries in accessing subsidies transferred to their bank accounts.

\subsubsection{Beneficiary Perception and Experience of Digitization}

Overall, as shown in Figure 4, 45 percent of beneficiaries said that the new system was better than the earlier method of obtaining subsidized cooking gas, with very few respondents expressing a negative opinion of the reform. The positive perceptions are overwhelmingly due to two factors (Figure 7): the easy availability of cylinders with less waiting time for refills and a reduction in black market diversion of cooking gas. These responses confirm that diversion was indeed seen as a problem under the old system, although it may be difficult to get an exact idea of its extent. However, 52 out of the 185 respondents who liked the new system also indicated as a reason that they were able to receive other benefits in the same bank account. This suggests that the PAHAL transfers have acted as a catalyst for them to use the banking system. Among the few who had a negative opinion, the most common reason was the high upfront payment for the cylinder. This is a valid concern, especially for the new connections for rural women from BPL families through Ujjwala. 


\section{Figure 7. Reasons cited for liking the new PAHAL system}

There is less waiting time for cylinders now

Black marketing has reduced

No shortage of cylinders and it is easily available

I get other benefits in the same account

I save the cash in my bank account

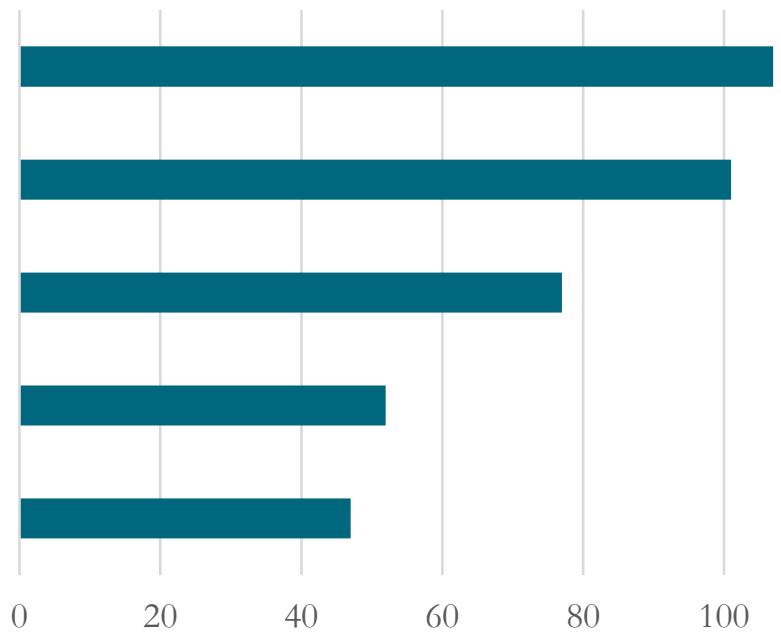

120

185 respondents; Multiple responses possible

PAHAL is implemented by the federal government and is not part of the Bhamashah program. Therefore, not all PAHAL subsidies (outside the Ujjwala program) are delivered to a bank account which is in the name of a woman. While around 45 percent stated that the account belongs either to the Bhamashah head or to some other female member of the household, half of the accounts are those of the male member of the household. This is particularly true of families in higher income groups and those owning land above half an acre. This is probably because clean cooking gas was the preserve of the relatively well-off both in urban and rural areas before the current drive to expand the LPG consumer base to poor families.

Our econometric analysis suggests that BPL respondents are 14 percent more likely than APL respondents to say that the new system is better. Interestingly, women are 11 percent less likely than men to have a positive perception, but we did not disaggregate the data on the basis of their ownership of bank accounts where the subsidy is transferred. In an apparently counter-intuitive result, respondents are more likely to have a positive perception of the new system the further they are from banks or other cash sources. Also, as the time it takes for a family to get cash increases, so too does the probability that the PAHAL subsidy goes to a female's bank account. As might be expected, families who report receiving widow pensions are about 34 percent more likely to say that PAHAL subsidy goes to a female's bank account.

From these results, it is clear that the convenience of being able to access cylinders as needed rather than see the cylinders diverted to the market by dealers generally outweighs any inconvenience of having to draw the subsidy from a bank account. The apparently counterintuitive result on distance to a bank branch may reflect greater vulnerability to diversion by more remote customers, who previously had even less recourse when cylinders failed to arrive. 


\subsection{Social Pensions: From Postal Delivery to Direct Benefit Transfer into Bank Accounts}

\subsubsection{Process of Digitization}

India has an extensive system of social pensions as part of its welfare program for the poor and the elderly, under the umbrella of the National Social Assistance Program (NSAP). Funded primarily out of the federal budget and administered by the Ministry of Rural Development (MoRD), the program currently has over 33 million beneficiaries nationally, or approximately 2.5 percent of the total population. At present, the NSAP beneficiaries comprise mainly of Old Age Pension (NOAPS), Widow Pension (NWPS) and Disability Pension (NDPS) Schemes. The benefit itself is small-the federal government contributes between Rs.200-500 (\$3-7.5) per month and state governments may contribute an equal or greater amount to increase the benefit.

Rajasthan has approximately 5 million NOAPS, 1 million NWPS and 0.5 million NDPS beneficiaries. Pensions have traditionally been delivered using money orders or in cash through postmen. While this ensured doorstep delivery for people with limited mobility, it also created inconvenience due to irregularity of delivery and commissions charged by postmen (Microsave, 2017).

To address these issues, the Rajasthan government started the process of digitizing the list of pension beneficiaries from 2015 onwards, seeding their Aadhaar numbers in the pension database and linking them with their bank accounts. The two-fold objective was to eliminate ghost and duplicate entries from the list of beneficiaries and improve pension delivery to bona fide beneficiaries in the form of direct transfer of benefits to their bank accounts. Our survey looked at pension beneficiaries' perceptions of the new delivery system and their experience of obtaining pensions through Aadhaar-linked bank accounts.

Of our sample, 21 percent report having a NOAPS beneficiary in their family, while only 3 percent receive a NDPS payment and 7 percent a NWPS pension. Even though the number of pensioners is less than the number of survey respondents, a few interesting results emerge from the responses. Of the beneficiaries whose pensions are currently deposited directly into their accounts, nearly 80 percent reported that they have experienced a change in the mode of delivery. Just over 20 percent did not experience a change in the system, presumably because they started receiving pensions after the new direct bank transfer system had been put in place. The most common prior mode of pension delivery was through the postman delivering at home (71 percent) while around a quarter of the beneficiaries personally went to the post office to collect their pensions.

Following the change in the delivery to direct transfer, almost all beneficiaries (93.6 percent) reported going to the bank personally to collect their pensions. This is true for both categories - those who experienced a change in the system as well as those who were already onboarded into the new system (Table 5). This also shows that cash withdrawal from banks remain the most preferred option for pension beneficiaries under the new system, with very little use of either E-mitras or banking correspondents. 
Table 5. Mode of withdrawal of pension

\begin{tabular}{|ccccccc} 
& \multicolumn{5}{c}{ How do you withdraw pensions now? } \\
\hline $\begin{array}{c}\text { Mode of } \\
\text { delivery } \\
\text { changed? }\end{array}$ & $\begin{array}{c}\text { I go to the } \\
\text { Bank }\end{array}$ & $\begin{array}{c}\text { Send someone } \\
\text { else to the } \\
\text { bank }\end{array}$ & $\begin{array}{c}\text { Withdraw } \\
\text { from e- } \\
\text { Mitra }\end{array}$ & $\begin{array}{c}\text { Withdraw } \\
\text { from BC }\end{array}$ & Row total \\
\hline No & 26 & 0 & 0 & 1 & 27 \\
\hline Yes & 92 & 4 & 2 & 1 & 99 \\
\hline Column total & 118 & 4 & 2 & 2 & 126 \\
\hline
\end{tabular}

\subsubsection{Beneficiary Perception and Experience of Digitization}

From Figure 4, the overall perception of the delivery reform seems to be overwhelmingly positive. Nearly two-thirds of the respondents felt that the new system is better than the old one, while around one-third were indifferent between direct bank transfers and postal delivery. Very few were negative even though, as noted previously, 5 percent of pensions were temporarily stopped when the new system was introduced.

Disaggregating the sample by BPL/APL status, we find that the positive perception of pension delivery reform was higher by nearly 25 percentage points for BPL beneficiaries as compared to non-BPL (Figure 8). Per the earlier discussion, NSAP pensions in Rajasthan involve relatively small transfers and therefore are likely to be more important for persons below the poverty line. The support for the direct bank transfer from BPL beneficiaries therefore suggests that the reform has had a positive impact on the poorest sections of the society.

In contrast to PDS and PAHAL where the reasons for the beneficiary's preference for the new system are clear, it is a little less obvious what is driving the strong positive perception regarding the change to the direct bank transfer system for pensions. Just over 16 percent of respondents felt that they got the full pension amount now compared to before, but 5 percent held the opposite view. Regularity seems more important. About one-third of the respondents reported that the regularity of pensions has changed; of these, 85 percent reported that pensions have become more regular. These beneficiaries are more likely to say that the new system is better (comparing responses with those who were neutral) at the 5 percent level of statistical significance using a Chi-square test.

The low number of "worse" responses mean that we are only able to compare responses statistically between those who thought the system was "better" or "neither better nor worse." Respondents who reported enjoying new technology (as a justification for liking the new PDS system) were 17 percent more likely to say that the new pension system is also better. There is no clear relationship with distance to a bank branch, with those close and far away more likely to prefer the new system of direct transfer. BPL families are 22 percent 
more likely to say that it is better than non-BPL families, although again, this only implies ambivalence rather than dislike.

Figure 8. Perception of pension delivery reform - by BPL category

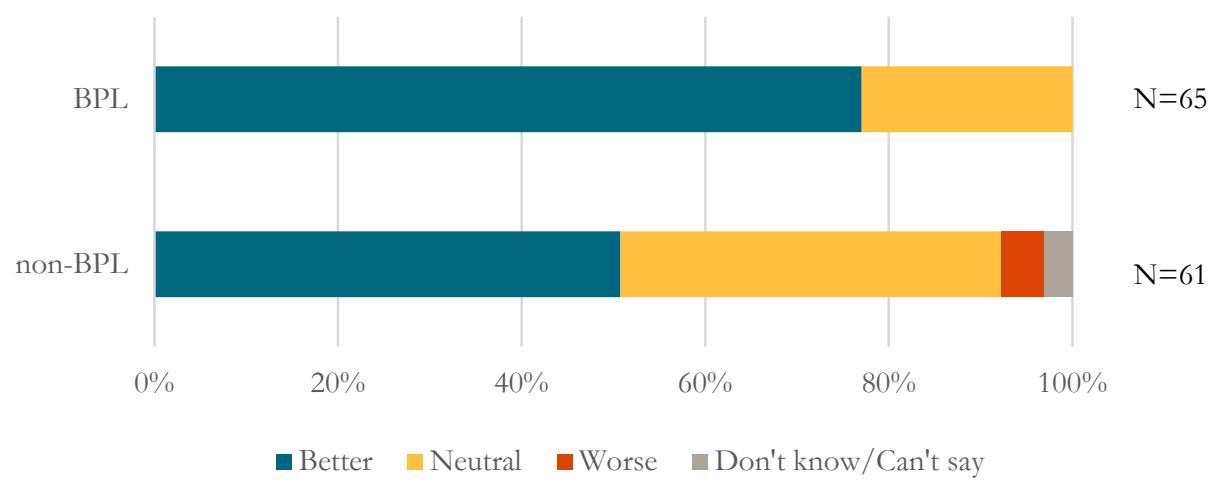

\subsection{Financial Inclusion and Women's Empowerment: Have Reforms Had Any Impact?}

India has made remarkable strides in financial inclusion over the last decade. Data from the Global FINDEX Survey indicates that bank account ownership for persons aged 15 and above has increased from 35 percent to a remarkable 80 percent between 2011 and 2017. Seventy-seven percent of women in this age group had a bank account in 2017 compared to only 26 percent in 2011. Indeed, the gender gap in financial access (as measured by ownership of an account) has also closed rapidly from 20 percent in 2014 to only 6 percent in 2017. In contrast to some other countries like Kenya, Tanzania and Bangladesh, where increases in financial inclusion have paralleled growth in the use of mobile money, almost all of the increase in India has been through formal banking institutions, following the launch of the Jan Dhan Yojana (JDY) in mid-2014. As the report notes, "this policy benefited traditionally excluded groups and helped ensure inclusive growth in account ownership" (Demirgüç-Kunt et. al., 2018, pp.19)

Data on financial inclusion from our survey in Rajasthan strongly corroborate these national level findings. Our analysis indicates that bank account ownership at the household level is now universal for the sample. A significant majority of households have more than one bank account and the number of households with multiple accounts is greater for rural compared to urban areas of the state (Figure 9). 


\section{Figure 9. Number of bank accounts per household}

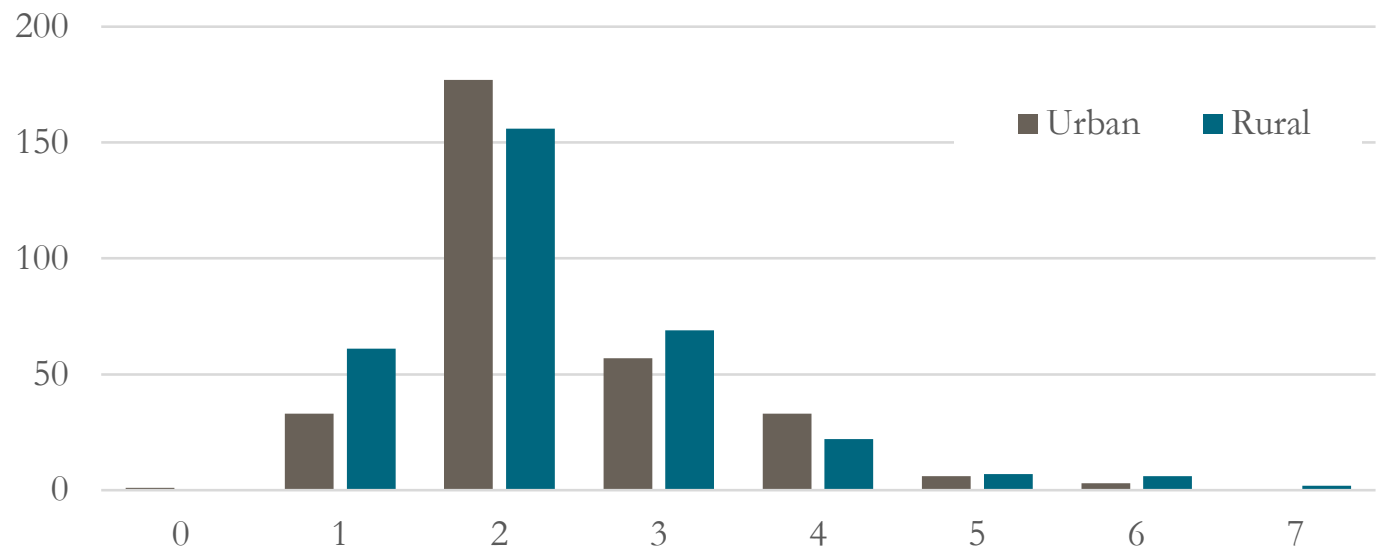

Both financial inclusion and women's empowerment are objectives of the Bhamashah program. As noted above, the approach to digital governance in Rajasthan has mirrored the overall JAM framework, with an additional layer of unique ID assigned to each family registered under the program. Bhamashah also mandates that a woman has to be designated as the head of the family and the database has to include her bank account and Aadhaar number. This provides the architecture of transferring benefits directly to her Aadhaar linked bank account and provides the option of linking the mobile number of any family member in the database to receive information on service delivery and payments.

Table 6. Income profile of women who opened bank accounts

\begin{tabular}{|c|c|c|}
\hline $\begin{array}{c}\text { Monthly family } \\
\text { income }\end{array}$ & $\begin{array}{c}\text { Percentage of women } \\
\text { who newly opened } \\
\text { bank accts }\end{array}$ & $\begin{array}{c}\text { Percentage of full } \\
\text { sample (N=633) }\end{array}$ \\
\hline < INR 2000 & 7 & 10 \\
\hline INR 2000-INR 5000 & 39 & 41 \\
\hline INR 5000-INR 10000 & 47 & 42 \\
\hline INR 10000 and over & 8 & 7 \\
\hline
\end{tabular}

Our data indicates that nearly 66 percent of women heads of household opened bank accounts at the time of Bhamashah registration. This indicates a huge push towards financial inclusion through the design of the program (Figure 10a). Almost 90 percent of these accounts have also been linked to Aadhaar (Figure 10b). Moreover, most of the women who opened bank accounts are in the bottom three income categories of the survey, indicating that the process of financial inclusion was highly equitable, and covered those women who would have otherwise probably been left out of the formal banking system (Table 6). The 
move towards digital programs appears to have improved both access and equity in extending the financial system to the hitherto unbanked women of Rajasthan.

Figure 10a. Share of new accounts of women head of households

Did Bhamashah head have a bank account before registration?

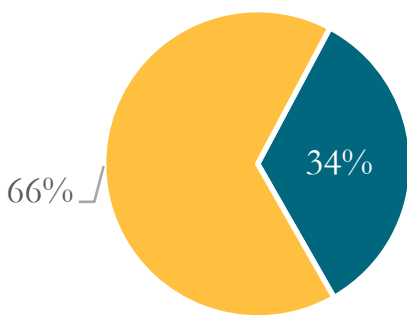

- Yes $₫$ No
Figure 10b. Linkage of Aadhaar with bank account of Bhamashah head of household

Is the bank account of Bhamashah head linked with Aadhaar?

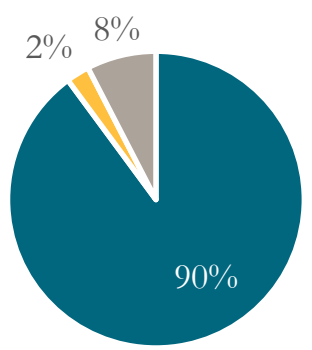

- Yes $\quad$ No $=$ Don’t know/Can’t Say

Further analysis builds on this finding. Only one-third of all Bhamashah heads of household had bank accounts before the launch of the program. Designated Bhamashah head of household for BPL families were 18 percent more likely to have had a bank account prior to Bhamashah registration than non-BPL families. On the other hand, women in landowning families are 15 percent less likely to have opened a bank account to receive the PAHAL subsidy than those who did not own land. Although women generally are 15 percent less likely to have opened a bank account to receive the PAHAL subsidy, women in BPL families are 15 percent more likely to say they opened a bank account to receive the PAHAL subsidy. This probably reflects the expansion of cooking gas connections to poorer rural women through the Ujjwala program, as noted in Section 4.2 above.

While it is too early to comment definitively on the impact of digital governance on women's empowerment, our data points to some signs of progress and as well as constraints. Our analysis indicates that women are indeed accessing financial services, with 54 percent of households reporting that women travel to withdraw cash most often, even more so when the cash point is not very close. However, as the distance to the cash point becomes longer, they are more likely to be accompanied by a male member of the family (Figure 11). Responses indicate several reasons why women may be accompanied, including the need for transport as well as the fact that many women are still not familiar enough with banks to transact on their own. Further investigation would be useful to better understand the constraints on women's agency and economic empowerment. 
Figure 11. How distance affects the gender of cash withdrawers

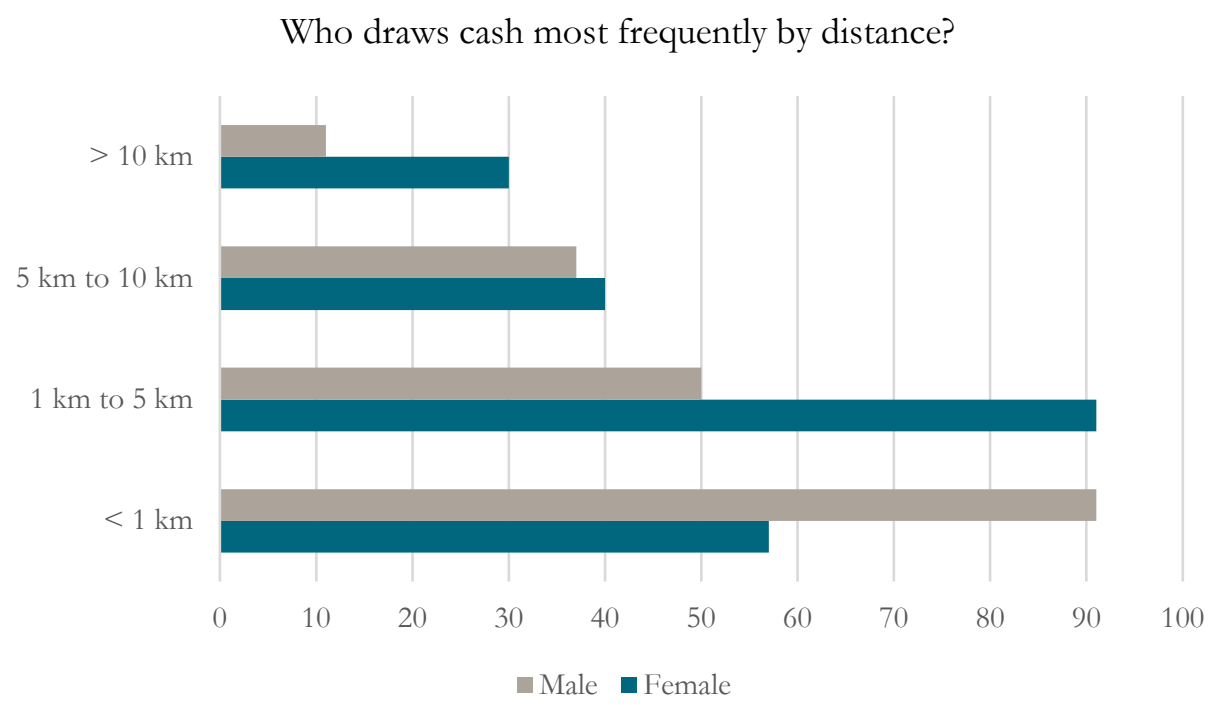

There is still a wide gender gap in digital literacy, taking the ownership and use of mobile phones as an indicator. In our survey, 94 percent of households possess a mobile phone and 75 percent reported that the number is mapped to the Bhamashah card. However, only 58 percent of all households include someone who can read or write text messages and in only 20 percent of households does the Bhamashah head of family use the mobile phone (Figures $12 \mathrm{a}$ and $12 \mathrm{~b})$.

\section{Figure 12a. Proportion of families with digitally literate members}

Someone in the family can read/write SMS?

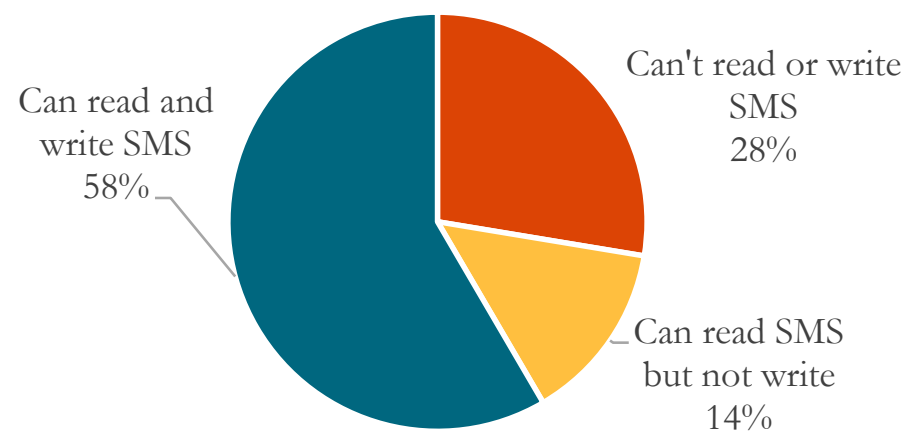


Figure 12b. Proportion of families with digitally literate (woman) head of family

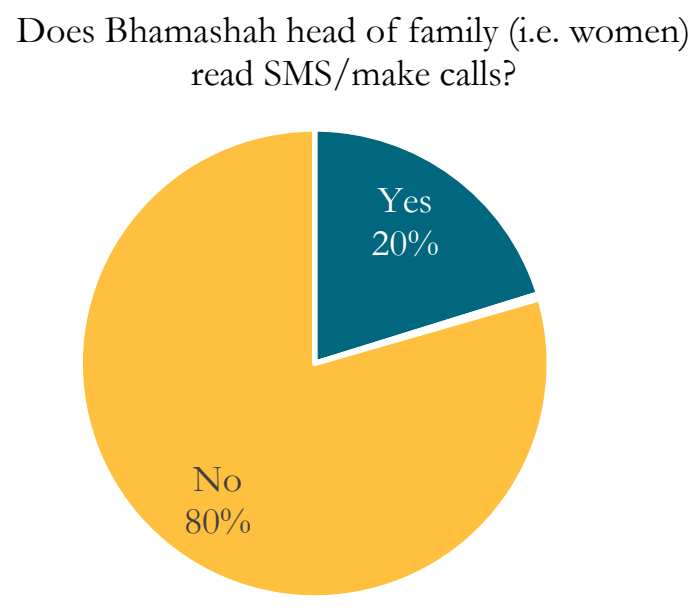

With the shift towards digital delivery of services, digital literacy is becoming a baseline competency for citizens and particularly for women if they are to take control of their finances and reap the full benefit of digital governance. In an increasingly digital environment, owning a mobile phone should be a boon for households. Indeed, our data shows that the families who own a mobile phone are more likely to find authentication easy and to have received the Bhamashah enrolment incentive. Also, when the Bhamashah head of household (almost always a female) can read messages and make phone calls, they are more likely to say the new PDS system is better. These findings are summarized in Table 7.

Table 7. Digital capability and experience of digital governance

\begin{tabular}{|ccc|}
$\begin{array}{c}\text { Family possesses at least } \\
\text { one mobile phone }\end{array}$ & $\begin{array}{c}\text { Received Bhamashah } \\
\text { enrollment incentive }\end{array}$ \\
\hline Yes & $72 \%$ & $41 \%$ \\
No & $54 \%$ & $17 \%$ \\
\hline $\begin{array}{c}\text { Bhamashah head of } \\
\text { household reads SMS } \\
\text { and makes calls? }\end{array}$ & $\begin{array}{c}\text { Think the new PDS system } \\
\text { is better }\end{array}$ & $\begin{array}{c}\text { Takes less time to obtain } \\
\text { cash }\end{array}$ \\
\hline Yes & $50 \%$ & $88 \%$ \\
No & $40 \%$ & $74 \%$ \\
\hline
\end{tabular}

Digital literacy has therefore emerged as a significant barrier to achieving the goals of women's empowerment in particular and equitable digital governance more generally. While the basic architecture is now in place, the focus needs to shift to remove the constraints that people face in accessing services. This can take the form of changes in design of programs as well as their implementation. On balance, and recognizing also the problems, survey results suggest that the perception of digital governance in Rajasthan is relatively positive. The 
challenge will be to maintain support for the program and further improve the experience of beneficiaries engaged with this new way of interacting with the state.

\section{Conclusion and Implications for Policy}

The reforms in Rajasthan are, of course, only one slice of the remarkable shift towards digitally-enabled programs that is being rolled out across India, combining Aadhaar, financial inclusion and mobile communications. The reforms are on a massive scale, with Rajasthan alone comparable to Germany in terms of area and population. While the LPG program is at national level, most programs are implemented by states, and these are shaping their reforms at different speeds and in somewhat different ways. India is therefore a laboratory for digital reforms of governance and service delivery. There is no guarantee, of course, that

Rajasthan's experience will carry over to other states, but all evidence is useful, including for the many other countries that are also moving towards the use of digital technology for program delivery.

How should we assess the reforms? One criterion could be greater efficiency, as measured by lower fiscal and implementation costs for comparable services. Another could be better service delivery, as seen by the clients of the programs. There may also be some crosscutting objectives that are seen as desirable in their own right, such as financial inclusion and women's empowerment. And, of course, we need to take into account the transitional costs associated with the shift towards digital programs. Debate on the reforms has been contentious in India, but with still limited empirical evidence there has perhaps been more sound than light. In this study, we have tried to narrow the evidence gap, at least in the area of service quality, by surveying a sample of households in Rajasthan to see whether they consider the new systems to be better or worse and to understand the reasons for their opinions. We did not engage with the state government on possible changes in the fiscal costs of the programs.

Rajasthan is neither the most digitally-advanced state nor the least. It is distinctive in having reorganized its programs, including for PDS and pensions, into the state-level Bhamashah scheme centered on the nuclear family. This offers both an opportunity and a challenge for research. The opportunity arises because one of the goals of Bhamashah is to empower women by designating them as the head of the household for program purposes, adding another dimension to the objectives. The challenge is to distinguish views on changes in the efficiency of PDS, pension and other delivery systems from those on the (sometimes painful) reorganization process into digital programs within the Bhamashah system. We have tried to distinguish views on these questions, but cannot be completely confident of success because the difference might not always be clear to the people affected by the changes.

Our conclusion on reorganization into digital programs is that this has not been straightforward. Data errors and inconsistencies need to be resolved and identifiers need to be seeded correctly into beneficiary rolls. In Rajasthan, the problems were compounded by the need to trim back the numbers of BPL families that access PDS following the unintended expansion of this category; rolling back the number was a less than transparent process and led to the exclusion of some people who believed (correctly or otherwise) that 
they should have been included. Pension payments were temporarily interrupted for about 5 percent of beneficiaries during the transition. A number of respondents expressed reservations about the private-sector based model of assistance (E-mitras) that was supposed to help people to navigate the difficulties of moving to the new digital service delivery platform. Few of those entitled to the Rs. 2000 sign-on bonus for the Bhamashah program appear to have received it; few were aware of the other benefit — health insurance - offered by the program. Transitions need careful preparation, with effective communication and particular attention to the effective management of disputes and grievances.

Despite these difficulties, on balance the reforms appear to have improved service delivery. The three programs covered are of different types: PDS provides in-kind subsidized rations while PAHAL has transitioned LPG subsidies from prices to a voucher-type program of direct deposits into bank accounts. The pension reform shifted the mode of delivery from manual payment through the post office towards direct deposits into bank accounts. Together, these three programs cover essentially all of the possible mechanisms (in-kind, voucher and money) for providing subsidies and benefits. In all three programs, the proportion of people preferring the new systems, at 40-60 percent, far exceeded the proportion who expressed a preference for the old system (5-12 percent). This is a significant finding from the study.

Why did people express these preferences? In the case of PDS and PAHAL the answer is clear-they considered that the new systems gave them greater control over their entitlements and reduced the ability of others to claim their benefits or divert them. Especially considering the inconveniences associated with the new systems-having to travel to banks to collect the PAHAL subsidy and having to be authenticated to receive rationsthis confirms that diversion was indeed seen as a serious problem under the old systems by many beneficiaries. The results cannot prove that diversion was actually reduced, but if it was not, or had never existed in the first place, it is difficult to see why respondents answered as they did. It would also be hard to justify the large increased in dealer margins that were considered necessary to sustain the ration system because of fewer opportunities to divert benefits.

In the case of pensions the answer is a little less clear; while an expressed improvement in the regularity of pension delivery is a significant predictor of preference for the new system, only about one third of respondents reported improved regularity. There were also more cases of pensioners asserting that they received a greater proportion of their pensions under the new system than the reverse, but the numbers are small. However, the preference for the new system is overwhelming, with very few indicating a preference for post office delivery. The responses indicated some other positive responses, such as the ability to use bank accounts for other purposes and, in some cases, a liking for new technology.

These results are encouraging for the new approaches. They suggest that -as found in other cases - most people welcome technology provided that it is seen to deliver useful services (Gelb \& Diofasi Metz, 2018). Of course, there will always be some people who have difficulties in navigating the new systems (see below) and who will need assistance. 
On the negative side, in addition to transitional costs the responses confirm some weaknesses in the new systems. For PDS, by far the greatest problems were those associated with authentication. Although 96 percent of respondents indicated that they were generally authenticated after 3-4 fingerprint attempts or less, only 24 percent were usually authenticated at the first attempt. This performance is far inferior to that presented in the Aadhaar proof-of-concept studies released in $2012 .{ }^{9}$ Moreover, failure to authenticate meant, at the very least, severe inconvenience, with beneficiaries required to bring other family members or come back another day. Dealers did not seem to be trained in Best-FingerDetection; neither did they implement backup protocols such as iris or OTP. In none of the few cases in which such protocols were followed did respondents rate the new system as worse than the old one. Connectivity was also a problem for PDS, though less serious than authentication. The main concern with the LPG program was the upfront cost of cylinders, a serious issue especially as the program is rolled out to poorer households through the Ujjwala scheme targeted at poor women in rural areas.

There are clear lessons for other biometric programs. Especially if authentication at point-ofservice is considered to be essential (and this needs careful case-by-case justification), it is vital to ensure a wide range of options and to train providers properly. It is notable that Andhra Pradesh, possibly the most advanced state in the use of digital delivery, has mandated a human option as a last resort; the Village Revenue Officer is required to authenticate on behalf of a villager unable to do so. ${ }^{10}$ More research is needed on authentication in the field.

Are difficulties with the new systems resulting in people actually being denied entitlements, including food rations? Unfortunately, our survey is not able to throw a conclusive light on this critical question. While quite a number of people respond that they would be "denied" rations if they fail to be authenticated, they were allowed to include multiple responses such as "told to come back another day"; moreover, many of those who responded "denied" reported that their fingerprints were verified in 1-2 attempts or indicated a preference for the new system over the old one. It is therefore likely that some of the respondents interpreted the question as a hypothetical "what if" or interpreted "denied" as part of a set of steps to follow up after the failure. We are attempting to frame the question more precisely in ongoing research.

Among the surprises, we had expected certain groups to fare better than others with the new systems. Farmers and the elderly might have more difficulty in authenticating themselves for PDS using fingerprints than others; people located further away from banks might have been expected to be less positive about PAHAL or pension reforms that deposited benefits into bank accounts, especially as Rajasthan has not seen much growth in mobile bank

\footnotetext{
${ }^{9}$ In these POC tests, for a single best finger the sum of Failure-to-Capture and False Reject Rate was only 5 percent for a False Accept Rate of 0.01 percent (the same as for a 4-digit PIN). This suggests that about 95 percent of people should have been authenticated at the first attempt (Gelb \& Clark, 2013).

10 Again, this echoes other studies, such as those on attitudes to e-Gates, which find that travelers are generally happy with automated recognition systems that speed transitions through airports, provided that there is human help at hand when they fail (Gelb \& Diofasi Metz, 2018).
} 
correspondents. But the differences in responses are less systematic than we had anticipated, suggesting that other factors, such as the variable expertise of operators, are more important. It is also possible that those far from banks were even less well served by the previous system, because of greater dependence on less regular delivery systems.

Finally, the results throw some light on the two cross-cutting objectives of financial inclusion and gender empowerment. There is no doubt that reforms in Rajasthan have contributed to the massive boost in financial inclusion seen in India. Virtually all respondents have bank accounts, often two or more per family, as do all Bhamashah heads of household. Two thirds of these women had not owned bank accounts before the reforms. Responses also indicate that women are transacting on bank accounts, but often accompanied by males of the household. The most frequent reason given for this was that the woman was not literate and that she had little or no experience in dealing with banks; transport was also a factor. Very few responses cited cultural factors - that it was not right for women to have bank accounts. Clearly, attitudes to women will take years to evolve, but in the famously patriarchal context of Rajasthan this is encouraging.

Mobiles emerge, however, as a male preserve. Most are held by men; many women are not able to read or write SMS's or operate a mobile phone. Together with some evidence that those more connected and with more capacity seem to have been more able to navigate the reforms better, this suggests a further frontier for policies and programs to shift India towards a digital society — ensuring that all people have the capacity to access and to use digital technology. Estonia, perhaps the world leader in this area, did exactly that, with public-private partnerships educating more than 100,000 people (almost 10 percent of the population) in how to navigate the new digital ecosystem. Rajasthan should do the same. 


\section{References}

Abraham, R., Bennett, E., Sen, N., \& Buddy Shah, N. (2017). State of Aadhaar Report 2016-17. IDinsight. Retrieved from http://stateofaadhaar.in/wp-content/uploads/State-ofAadhaar-Full-Report-2016-17-IDinsight.pdf.

Atansah, P., Khandan, M., Moss, T., Mukherjee, A., \& Richmond, J. (2017). When Do Subsidy Reforms Stick? Lessons from Iran, Nigeria, and India. Center for Global Development. Retrieved from https://www.cgdev.org/sites/default/files/when-do-subsidy-reformsstick-lessons-iran-nigeria-and-india.pdf.

Brant, R. (1990). Assessing Proportionality in the Proportional Odds Model for Ordinal Logistic Regression. Biometrics, 46(4), 1171-1178. doi:10.2307/2532457

Comptroller and Auditor General of India. (2016). Report of the Comptroller and Auditor General of India on Implementation of P AHAL (DBTL) Scheme (Pratyaksh Hanstantrit Labh Yojana). Union Government (Commercial) Ministry of Petroleum and Natural Gas. Retrieved from https://www.cag.gov.in/sites/default/files/audit report files/Union Commercial Co mpliance_Full_Report_25_2016_English.pdf

Demirgüç-Kunt, A., Leora K., Dorothe S., Saniya A., \& Hess, J. (2018). The Global Findex Database 2017: Measuring Financial Inclusion and the Fintech Revolution. World Bank:

Washington, DC. Retrieved from https://globalfindex.worldbank.org/\#data sec focus.

Drèze, J., Khalid, N., Khera, R., \& Somanchi, A. (2017). Aadhaar and Food Security in Jharkhand. Economic \& Political Weekly, 52(50), 51. Retrieved from http://www.im4change.org/siteadmin/tinymce/uploaded/Aadhaar $\% 20$ and $\% 20$ Food $\%$ 20Security $\% 20$ in $\% 20$ Jharkhand $\% 20$ Pain $\% 20$ without $\% 20$ Gain.pdf.

Dutta, B. and Ramaswami, B. (2011). Targeting and efficiency in the public distribution system: Case study of Andhra Pradesh and Maharashtra. Economic and Political Weekly, 36(18), 1524-1532

Gelb, A., \& Diofasi Metz, A. (2018). Identification Revolution: Can Digital ID be Harnessed for Development? Center for Global Development: Washington, DC.

Gelb, A., \& Clark, J. (2013). Performance lessons from India's universal identification program. CGD Policy Paper, 20. Retrieved from https://www.cgdev.org/sites/default/files/biometric-performance-lessons-India.pdf.

George, S. \& Subramanian, A. (2016). Clearing the air on LPG. The Indian Express. Retrieved from http://indianexpress.com/article/opinion/columns/clearing-the-air-on-lpg-directbenefit-transfer-subsidies/.

International Telecommunications Union. (2018). Statistics. International Telecommunications Union. Retrieved from https://www.itu.int/en/ITUD/Statistics/Pages/stat/default.aspx.

Khera, R. (2011). Trends in diversion of PDS grain. Economic and Political Weekly, 46(21), 106114

Khera, R. (2017). Impact of Aadhaar in Welfare Programmes. Retrieved from https://papers.ssrn.com/sol3/papers.cfm?abstract id=3045235.

Long, J.S. \& Freese, F. (2001). Regression Models for Categorical Dependent Variables Using Stata. Stata Press Publication: College Station, Texas, pp 137-142. 
Mittal, N., Mukherjee, A., \& Gelb, A. (2017). Fuel Subsidy Reform in Developing Countries: Direct Benefit Transfer of LPG Cooking Gas Subsidy in India. Center for Global Development. Retrieved from https://www.cgdev.org/sites/default/files/fuel-subsidy-reformdeveloping-countries-india.pdf.

MicroSave. (2017). Household Perception: Impact of Bhamashah on Digital Governance Reforms in Rajasthan. MicroSave: Lucknow, India. Retrieved from http://www.microsave.net/files/pdf/171212 Household Perception Impact of Bha mashah Digital Governance Reforms in Rajasthan.pdf.

Muralidharan, K., Niehaus, P., \& Sukhtankar, S. (2016). Building state capacity: Evidence from biometric smartcards in India. American Economic Review, 106(10), 2895-2929.

Retrieved from https://www.aeaweb.org/articles?id=10.1257/aer.20141346.

Overbeck, D. (2016). Leakage and corruption in India's public distribution system.

Manuscript. Institute for Studies in Industrial Development, New Delhi. https://www.isid.ac.in/ epu/acegd2016/papers/DanielOverbeck.pdf (Accessed on July 2, 2018) 


\section{Annex 1: Sampling Frame}

\section{Quantitative research coverage details}

- Sample size of 633 covered

- 1 District per each of 7 administrative division covered $=7$ Districts

- District selected on the basis of the proportion of population covered by National Food Security Act (NFSA) entitlement for food rations that is closest to the average for the administrative division

- 2 Blocks per district (1 Rural \& 1 Urban) selected on the basis of minimum deviance from district NFSA coverage

- Villages and urban wards selected randomly (5-6 Villages per block, 2-3 urban wards)

- Minimum of 86 respondents per block allocated in proportion to the urban-rural population share in the block.

Number of respondents - Blockwise $(\mathrm{N}=633)$

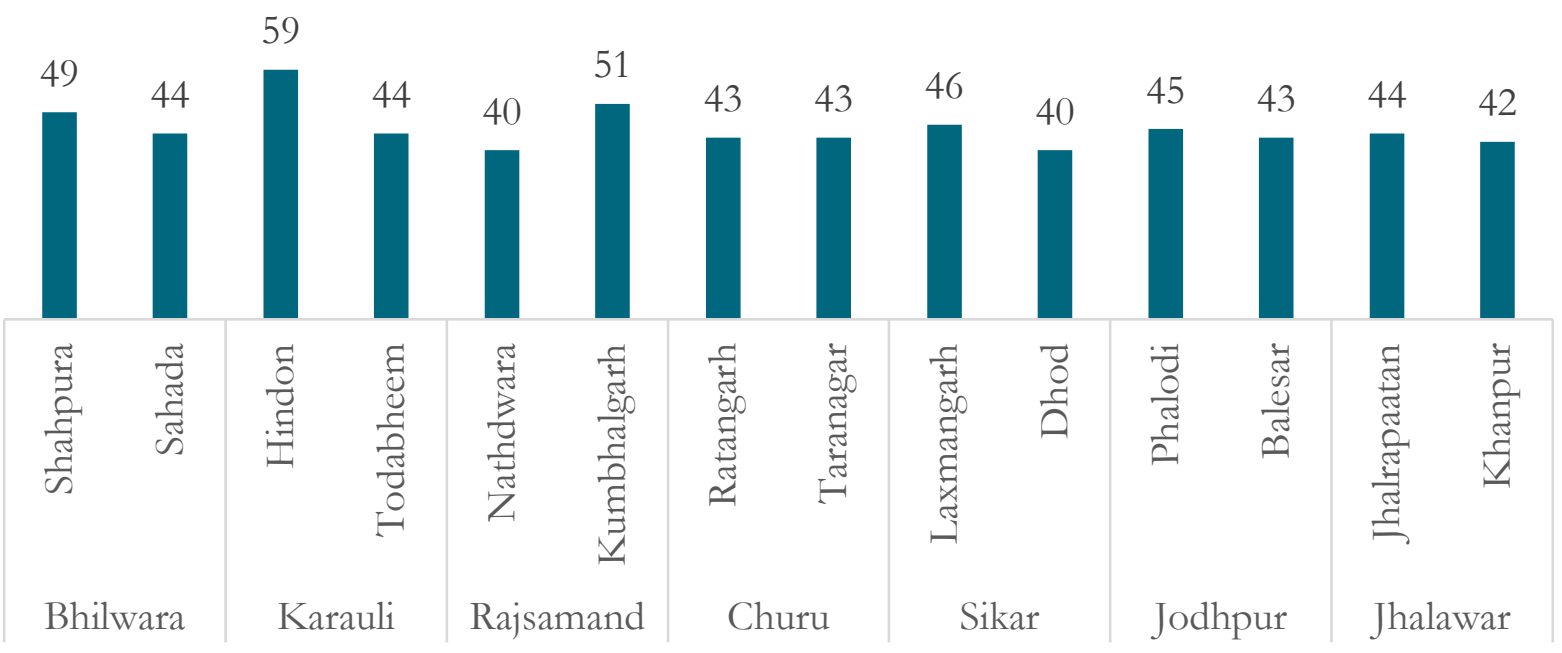

\section{Qualitative research coverage details}

- Focus group discussions (FGD) and Key Informant (KI) interviews conducted in districts selected for quantitative survey

- 4 Districts from 4 divisions covered to reflect the geographical diversity in the state

- Minimum of 2 blocks covered in each district, chosen purposively to ensure socioeconomic diversity within the district 


\begin{tabular}{|c|c|c|c|}
\hline District & No. of FGDs/KIs & Member strength & $\begin{array}{c}\text { Stakeholder } \\
\text { interviews }\end{array}$ \\
\hline Rajasmand & 9 & 43 & 7 \\
Bhilwara & 9 & 36 & 4 \\
Jodhpur & 6 & 36 & 2 \\
Karauli & 7 & 46 & 3 \\
\hline
\end{tabular}

